\title{
Assessing risks and uncertainties in forest dynamics under different management scenarios and climate change
}

\author{
Matthias Albert*, Jan Hansen, Jürgen Nagel, Matthias Schmidt and Hermann Spellmann
}

\begin{abstract}
Background: Forest management faces a climate induced shift in growth potential and increasing current and emerging new risks. Vulnerability analysis provides decision support based on projections of natural resources taking risks and uncertainties into account. In this paper we (1) characterize differences in forest dynamics under three management scenarios, (2) analyse the effects of the three scenarios on two risk factors, windthrow and drought stress, and (3) quantify the effects and the amount of uncertainty arising from climate projections on height increment and drought stress.
\end{abstract}

Methods: In four regions in northern Germany, we apply three contrasting management scenarios and project forest development under climate change until 2070. Three climate runs (minimum, median, maximum) based on the emission scenario RCP 8.5 control the site-sensitive forest growth functions. The minimum and maximum climate run define the range of prospective climate development.

Results: The projections of different management regimes until 2070 show the diverging medium-term effects of thinnings and harvests and long-term effects of species conversion on a regional scale. Examples of windthrow vulnerability and drought stress reveal how adaptation measures depend on the applied management path and the decision-maker's risk attitude. Uncertainty analysis shows the increasing variability of drought risk projections with time. The effect of climate projections on height growth are quantified and uncertainty analysis reveals that height growth of young trees is dominated by the age-trend whereas the climate signal in height increment of older trees is decisive.

Conclusions: Drought risk is a serious issue in the eastern regions independent of the applied silvicultural scenario, but adaptation measures are limited as the proportion of the most drought tolerant species Scots pine is already high. Windthrow risk is no serious overall threat in any region, but adequate counter-measures such as species conversion, species mixture or reduction of target diameter can be taken. This simulation study of three silvicultural scenarios and three climate runs spans a decision space of potential forest development to be used for decision making. Which adaptation measures to counteract climate induced risks and uncertainty are to be taken is, however, a matter of individual risk attitude.

Keywords: Climate change; Silvicultural management strategies; Site-sensitive growth model; Scenario simulation; Vulnerability analysis; Drought stress; Windthrow risk; Uncertainty

\footnotetext{
*Correspondence: matthias.albert@nw-fva.de

Northwest German Forest Research Station, Göttingen, Germany
} 


\section{Background}

Vulnerability (see Table 1 for definition) analysis has played an important role in forestry since Carlowitz (1713) introduced the principle of sustainability provoked by the exploitation of forests. Even more today, multi-functional forest management in central Europe faces new threats as climate change induces shifts in forest growth potential as well as increasing current and emerging new abiotic and biotic risks (Lindner et al. 2010; Seidl et al. 2010; see Table 1 for definition). Consequently, Millar et al. (2007) promote adaptive forest management strategies because knowledge about past forest conditions, forest dynamics and the corresponding suitable management options is not sufficient in an environment of new threats with yet relatively unknown forces and multiple factors of uncertainty (see Table 1 for definition). Bolte et al. (2009) concretize adaptive forest management strategies for central Europe proposing conservation of forest structures, active adaptation and passive adaptation as three possible concepts. A first step towards adaptation measures is a vulnerability assessment which in itself is no easy task. Turner et al. (2003) state that the complexity of factors, processes and various requirements by society and stakeholders complicate a comprehensive vulnerability assessment. Nevertheless, it is essential to provide profound support for decision-makers in land-use management based on feasible projections of natural resources taking risks and uncertainties into account.

Generally, the current state of a forest region can be characterized by different sustainability indicators including also measures to describe the forests' stability and resilience towards multiple abiotic and biotic hazards (see Table 1 for definition). Different planning strategies within the range of ecologically and socio-economically sound developments lead to diverging future states. The interdisciplinary research project "Sustainable land-use management in the North German lowlands" investigates the opportunities, challenges and potential conflicts in the

\section{Table 1 Definition of terms}

\begin{tabular}{ll}
\hline Term & Definition \\
\hline Hazard & $\begin{array}{l}\text { Threatening event within a given time period and area } \\
\text { (United Nations Department of Humanitarian Affairs 1992) }\end{array}$ \\
Vulnerability & $\begin{array}{l}\text { Degree to which natural resources are susceptible to } \\
\text { loss or damage on being exposed to a certain hazard } \\
\text { (Adger 2006) }\end{array}$ \\
Risk & $\begin{array}{l}\text { Probability of expected loss or damage due to a particular } \\
\text { hazard for a given area and reference period; mathematically } \\
\text { the product of hazard and vulnerability (United Nations }\end{array}$ \\
& $\begin{array}{l}\text { Department of Humanitarian Affairs 1992) } \\
\text { Situation where the current state of knowledge is } \\
\text { incomplete due to (1) lack of information, (2) imprecision } \\
\text { in model projections, and (3) unknown preferences in } \\
\text { decision making (cf. Ascough et al. 2008) }\end{array}$ \\
\hline
\end{tabular}

fields of agriculture, forestry and water management by analysing the effect of silvicultural and agricultural management alternatives on natural resources, their economical evaluation and the ecological value. Special emphasis is given to vulnerability analysis taking climate change into account. In particular, the analysis of diverging effects on forest dynamics due to silvicultural management alternatives can be used to identify adaptation measures.

The overall goal of this study is to deduce forest management options in the face of climate change by comparing forest dynamics in four regions in northern Germany. The four regions display different current species compositions and age class distributions. Already nowadays, regional vulnerability seems to increase from west to east on the grounds of climatic conditions and soil properties. Under climate change, vulnerability will possibly increase even more but not necessarily equally in every region. Thus, this comparative simulation study might depict regionally specific risks and consequently adaptation measures. We use two simulation approaches to deal with our research goals. Simulation approach 1 applies three silvicultural scenarios and one climate projection. Simulation approach 2 contains only one silvicultural scenario but three climate projections. In the presented analysis we pursue three specific objectives: (1) to characterize differences in forest dynamics under three contrasting silvicultural management strategies as a prerequisite to analyse risks and uncertainties (approach 1), (2) to quantify the effects of different silvicultural practices on the vulnerability to drought stress and windthrow hazard (approach 1), and (3) to quantify the effects and the amount of uncertainty on forest growth and drought stress due to climate change (approach 2).

\section{Methods}

The core of the forest simulation framework WaldPlaner 2.1 (Hansen and Nagel 2014) is a site-sensitive single tree growth model. The growth model consists of statistical functions basically describing tree height development, diameter growth and changes in crown dimensions. Soil and climate parameters directly affect tree height development which is predicted using the longitudinal height-diameter model by Schmidt (2010). However, tree diameter and crown dimensions are indirectly projected site-sensitively as tree height is an important predictor to estimate crown dimensions and these in turn have a major impact on diameter growth.

\section{Forest data}

The presented research is conducted in four regions Diepholz, Uelzen, Fläming and Oder-Spree all located in the north German lowlands (Figure 1 and Table 2).

Total forest area, forest proportion and mean stand size increase from west to east in the four regions. The 
climatic water balance indicates a higher aridity in the two eastern regions Fläming and Oder-Spree compared to the two western regions.

As the starting basis for the projection of forest development, approximately 1000 stands are sampled on a regular grid from the population of all stands with available yield data in every region. The sampling universe, though, does not cover every forested area since for certain stands yield data is missing or incomplete. Thus, the sampling points do not exhibit a constant representative factor of the area. We assume that the data availability is not correlated to the value of major site and stand parameters, thus the samples suffice to estimate the distribution of these site and stand parameters. The results from the samples are extrapolated to the entire regions using strata specific weights, calculated as follows:

$$
g_{i j}=F_{i j} / f_{i j}
$$

where $F_{i j}$ : by stand type $j$ and age class $i$ stratified area proportion of the sampling universe of all stands in a region with known tree species and age, $f_{i j}$ : by stand type $j$ and age class $i$ stratified proportion of the sample.

Each sample stand thus represents an area of $1 / n \times g_{i j}$ of the total forest area of a region, with $n=874$ stands in Diepholz, $n=999$ in Uelzen, $n=1011$ in Fläming and $n=1003$ in Oder-Spree. Based on the information at each sampling point, i.e. for each occurring species age, mean diameter, mean height, site index, species proportion, stocking degree and volume per hectare, model stands of 0.2 ha in size with single trees are generated using the stand generation algorithm implemented in the WaldPlaner software (Hansen and Nagel 2014).

\section{Soil data}

Soil parameters as input variables for the site-sensitive forest growth projection are provided at each sampling point using a soil map of scale 1:1 Mio (Richter et al. 2007). To assign soil nutrient classes from 1 (poor) to 5 (rich) to each sampling point, the information of the soil map and model functions by Ahrends (2010a) are applied. Accordingly, the available soil moisture as defined by Overbeck et al. (2011) is estimated. Three groundwater classes are assigned, based on the long-term mean depth to water table (MDWT) using groundwater contours and digital terrain models. MDWT is further statistically transferred into the long-term lowest depth to water table which is regarded as the depth to water table during growing season. Table 3 presents characteristics of the three parameters soil nutrient class, groundwater class and available soil moisture based on $1.4 \mathrm{~m}$ soil depth.

The soil parameters in Table 3 are assumed constant over the projection period. This can be justified in the case of available soil moisture which is used as a substitute for soil water storage. And as we consider the site conditions during the growing season, winter precipitation will most likely fill the soil water storage. A change in soil nutrients is a rather long-term and quite complex process of temperature-driven mineralization and alteration. Niklińska et al. (1999) state that it is difficult to make reasonable predictions on changes of nitrogen turnover under climate change. Thus, we assume the effect of soil nutrient change as being negligible during the 60 -year projection period. The assessment of groundwater classes is rather coarse, thus it does not seem advisable to regard this parameter dynamically.

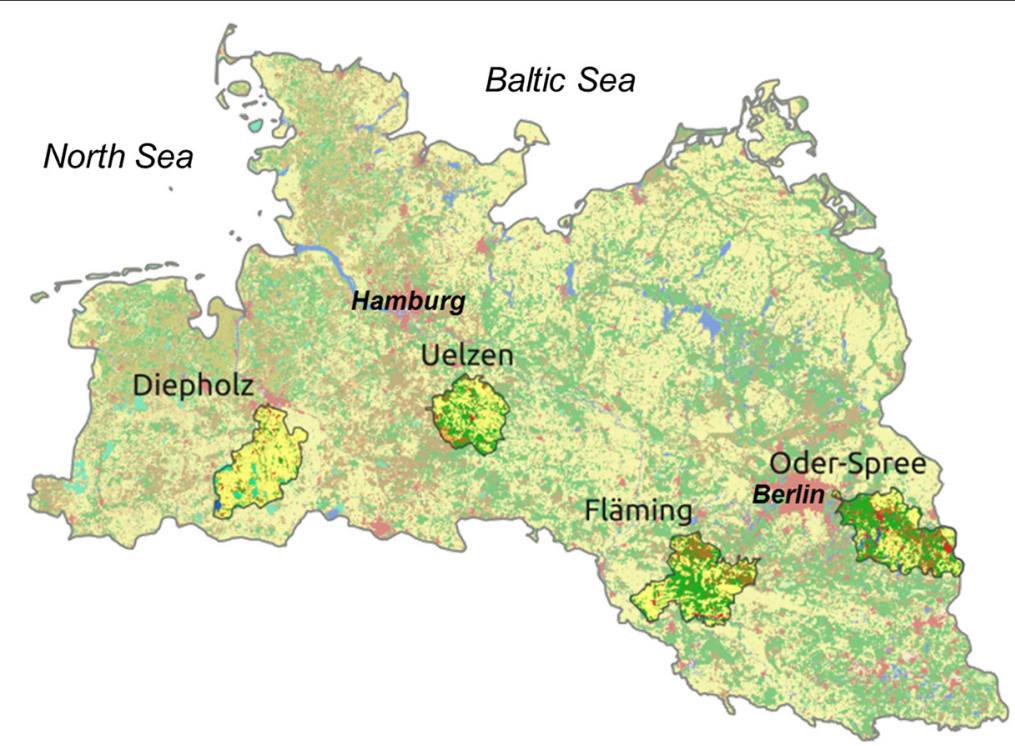

Figure 1 Location of the four research areas Diepholz, Uelzen, Fläming and Oder-Spree in northern Germany. 
Table 2 Characteristic numbers of research areas

\begin{tabular}{lllll}
\hline & Diepholz & Uelzen & Fläming & Oder-Spree \\
\hline Forest area (ha) & 15.042 & 45.712 & 51.368 & 76.714 \\
Forest proportion (\%) & 6.7 & 34.7 & 41.5 & 48.7 \\
Mean stand size (ha) & 1.05 & 1.51 & 2.98 & 2.93 \\
Mean summer temp. $\left({ }^{\circ} \mathrm{C}\right)$ & 22.9 & 22.8 & 24.2 & 24.0 \\
Summer precipitation $(\mathrm{mm})$ & 210 & 215 & 180 & 188 \\
Climatic water balance $(\mathrm{mm})$ & -90.5 & -82.0 & -157.8 & -147.2 \\
\hline
\end{tabular}

Climatic water balance is the difference of precipitation and evapotranspiration for grass.

\section{Climatic data}

We choose the emission scenario representative concentration pathway 8.5 (RCP 8.5$)$ by IPCC to initialize climate projections (Moss et al. 2008). Although being the most fierce emission scenario among the proposed ones by IPCC (2013), today's observed emissions already surpass RCP 8.5 (Peters et al. 2013). A total of 21 median climate projections all driven by RCP 8.5 and generated by different global climate models were further transferred to the region of Germany using the regional climate model STARS II (Orlowsky et al. 2008). Based on the anomaly in 2100 to today's temperature we select three climate projections to account for the variability in climate change. The climate scenarios are a minimum climate run resulting in a $2^{\circ} \mathrm{C}$ increase projected by the global model INM-CM4 of the Institute of Numerical Mathematics Russian Academy of Science, a median run with a temperature increase of about $3.5^{\circ} \mathrm{C}$ projected by the ECHAM6 model of Max-Planck-Institute Hamburg, Germany, and a maximum run with the highest temperature increase of more than $5^{\circ} \mathrm{C}$ projected by ACCESS1.0 of the Commonwealth Scientific and Industrial Research Organisation and the Bureau of Meteorology (CSIRO-BOM).

Table 3 Characteristics of soil parameters on forest land in the four regions

\begin{tabular}{lllll}
\hline & Diepholz & Uelzen & Fläming & Oder-Spree \\
\hline NC & Proportion (\%) & & \\
2 & 6 & - & 25 & 49 \\
3 & 47 & 75 & 49 & 21 \\
4 & 24 & 7 & 23 & 29 \\
5 & 23 & 18 & 1 & 1 \\
GWC & Proportion (\%) & & \\
0 & 60 & 92 & 91 & 80 \\
1 & 17 & 5 & 7 & 15 \\
2 & 23 & 4 & 2 & 5 \\
asm (mm) & 196 & 110 & 123 & 116
\end{tabular}

NC: soil nutrient class with 2 = poor, 3 = medium, 4 = good, 5 = rich; GWC: ground water class with $0=$ no groundwater access, $1=$ low groundwater access, 2 = moderate to strong groundwater access; asm: available soil moisture.
The Potsdam Institut für Klimafolgenforschung (PIK) provided homogenised daily climate observations for the time period 1951 to 2010 originating from the German Weather Service and the corresponding three sets of scenario data (minimum, median, maximum) for the time period 2011 to 2070. For consistent climate parameters, the STARS II model was driven by the climate observations for the period 1951 to 2010 resulting in simulated climate parameters from 1951 to 2070. Based on these climate projections for Germany the temperature sum (temp) in the species-specific growing season and the aridity index (ari) are predicted annually for each meteorological station in Germany until 2070. In order to assign climate parameters to each sampling point, the hydrological model WaSIM-ETH which is driven by meteorological and physical site parameters, is applied by downscaling the projected values of all meteorological stations within a $20-\mathrm{km}$ radius around the sampling point with a distance-weighted regression model (Schulla 1997; Schulla and Jasper 2007). Thus, regionalized climate parameters are available on a $100 \mathrm{~m} \times 100$ m grid.

The temperature sum in the growing season and the aridity index are climatic predictors in the longitudinal height-diameter model. Based on the statistical model LNVAR by Menzel (1997, p $52 \mathrm{ff}$ ) the beginning of the growing season is species-specifically estimated. The end of the growing season is determined species-independently, modifying the approach by Wilpert (1990) and Walther and Linderholm (2006). Thus, either the temperature criterion defined as a 7-day-period with mean temperature below $5^{\circ} \mathrm{C}$ between July and October or the short day criterion, whichever is met first, terminates the growing season. Aridity index is defined as the ratio of annual precipitation $(\mathrm{mm})$ and mean annual temperature $\left({ }^{\circ} \mathrm{C}\right)+10$ (de Martonne 1926).

Figure 2 illustrates the development of both climate parameters, temperature sum in the growing season and aridity index, over time in the four regions for the simulation period 2011 to 2070 . The values are derived based on projections of STARS II using RCP 8.5.

The curves of temperature sum in growing season reveal increasing trends over time for all regions as well as 
a spatial trend with increasing values from west to east (Figure 2A). The aridity index displays a clear spatial trend with drier conditions in the east while the temporal trend is less obvious (Figure 2C). Comparing the development of climate parameters under the three climate runs, minimum, median and maximum, using Diepholz as an example, it is noticeable that the amplitude over time within a run is stronger than between the runs. Nevertheless, the minimum and maximum run seem to project more extreme values around the median run (Figure 2B and D).

\section{Longitudinal height-diameter model}

The basic model for a site sensitive prediction of the single-tree height to diameter relation originates from a reparameterized version of the Korf function (Lappi 1991). Schmidt (2010) applies a multi-stage approach to fit height-diameter models for Norway spruce, Scots pine, Douglas-fir, European beech and sessile and pedunculate oak in Germany. In the first stage dbh, tree age, relative $\mathrm{dbh}$, year of germination, temperature sum in the growing season, aridity index, height a.s.l. and spatial coordinates are used as predictors in a generalized additive model ( $\mathrm{gam}$ ) to predict tree height. The gam formulation allows the incorporation of nonlinear effects. Furthermore, the model is longitudinal and can be used for height prediction because tree age is a major explanatory variable. To further enhance the sensitivity of predictions to soil parameters a second model stage is applied.
Again, a generalized additive model is formulated, using the transformed tree height estimate of the first stage, available soil moisture, soil nutrient class and groundwater class as predictors (see Table 3 for parameter definitions). Separate modelling steps are necessary as soil information is not available nationwide but the wide range of climate values over Germany is beneficial to identify climatic effects. Finally, the longitudinal heightdiameter model is sensitive to spatially and temporal changing climatic conditions and to different soil properties.

In our simulation framework, the climate parameters vary according to climate projections whereas the soil parameters are assumed constant over time. Nevertheless, climate change affects tree height predictions differently depending on soil properties because of the multiplicative combination of both soil and climate parameters. Therefore, the longitudinal height-diameter model is soil and climate sensitive.

\section{Simulation framework WaldPlaner 2.1}

The simulation framework WaldPlaner 2.1 projects forest development by applying different silvicultural management regimes and accounting for changing climatic conditions. Figure 3 displays the major components of the WaldPlaner system.

The system needs three main data categories as input, i.e. data on forest stands, soil properties and climate conditions, all as described above.
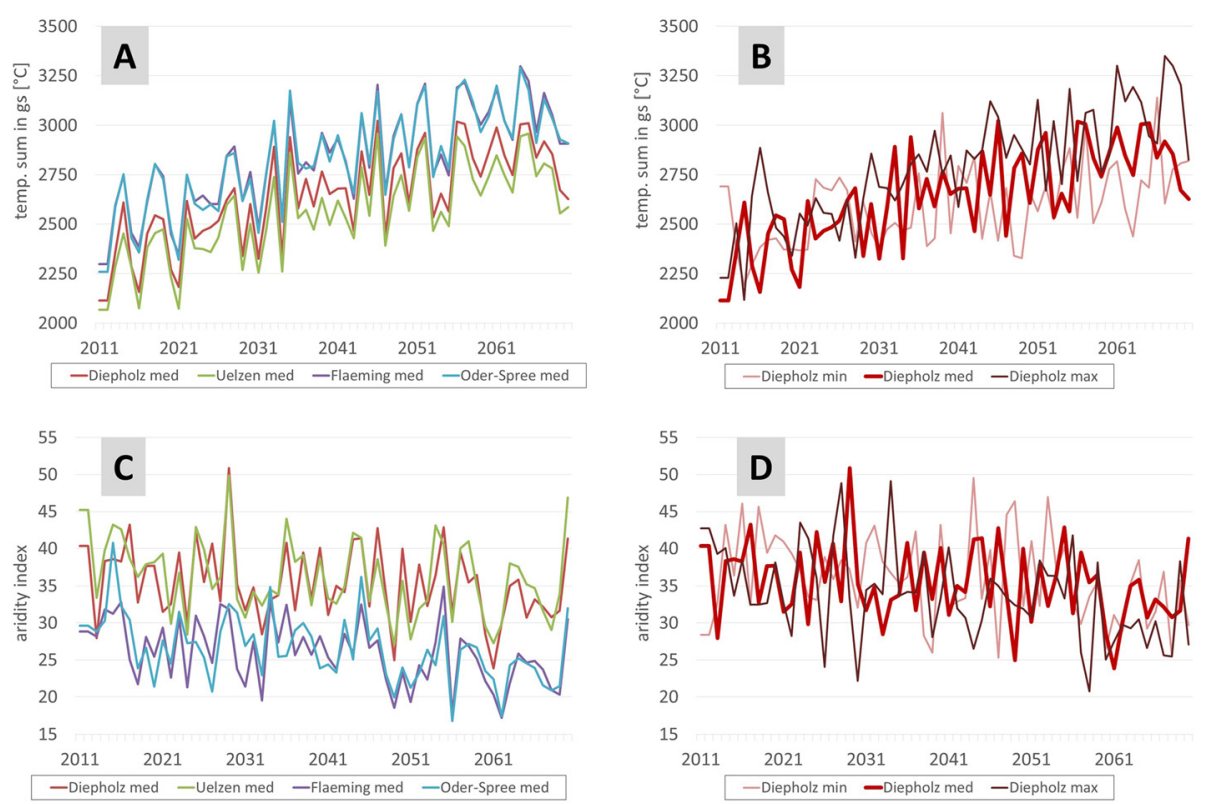

Figure 2 Climate parameters over time for the simulation period 2011 to 2070 projected with STARS II using RCP 8.5 (A: temperature sum in the growing season of the median climate run as mean regional values, $\mathbf{B}$ : temperature sum in the growing season of the minimum, median and maximum climate run as mean values in Diepholz, $\mathbf{C}$ : aridity index of the median climate run as mean regional values, $\mathbf{D}$ : aridity index of the minimum, median and maximum climate run as mean values in Diepholz). 
A list of control variables is used to define silvicultural management strategies and nature conservation rule sets. We apply three contrasting management scenarios, i.e. a reference scenario reproducing today's close-tonature silvicultural practices in Germany, a biodiversity run aiming at increasing the area of potential natural vegetation, and a climate protection run with the goal to maximize $\mathrm{CO}_{2}$ sequestration in standing volume and wood products. Table 4 lists the main characteristics of the control variables to reproduce the three management scenarios.

The nature conservation rule sets differ in the three management strategies according to the proportion of unmanaged area, the proportion of forest area managed in low intensive silviculture to conform to the florafauna-habitat (FFH) directive, the amount of deadwood and the number of habitat trees. The biodiversity path's objective can clearly be identified as a higher proportion of forest land will be totally unmanaged and the entire FFH-area will be developed towards the natural habitat type. The reference path and climate protection path are equal in matters of nature conservation taking these control variables into account.

An important indicator to differentiate between the management strategies is species conversion. For all management paths, the selection of future tree species always has to be in line with species suitability to site conditions. In the reference scenario, deciduous tree species are preferred as is defined by the principles of close-to-nature silviculture. In the biodiversity strategy, silvicultural practices intend to increase the area of natural vegetation, thus, tree species of potential natural vegetation are chosen. In the climate protection strategy a high $\mathrm{CO}_{2}$ sequestration can best be realized by high increment resulting in high standing volume and simultaneously harvesting a considerable mass of timber being used in long-lasting products such as construction wood. Therefore, fast growing conifer species are preferred. It is important to note that species conversion is only realized in the simulations when the existing stand is mature and harvested.

The control variables in the thinning and harvesting section all determine the speed of conversion. While harvesting of stands is delayed under the biodiversity run because of lower thinning intensity, a lower limit of thinning and harvesting volume per cut and higher target diameter for favored species it is the opposite under the climate protection path and the reference path taking an intermediate position.

In the simulation framework WaldPlaner with all input data and determining factors set forest development is projected starting with density induced mortality in every stand where occurrence is predicted (Hansen and Nagel 2014, p 138 ff.). Single tree growth is then predicted for a 5-year period from 2011 to 2015, taking site and period specific climate conditions as well as specific soil properties into account. Thinnings and harvests complete the first projection cycle. These 5-year cycles of mortality, growth and fellings are repeated until 2070 (Figure 3).

We analyze the effects of different management scenarios and climate projections on forest development excluding any risk induced impacts such as mortality or loss of vitality. After the undisturbed simulation, the management paths are evaluated taking risks into account. In particular, we conduct a risk analysis looking

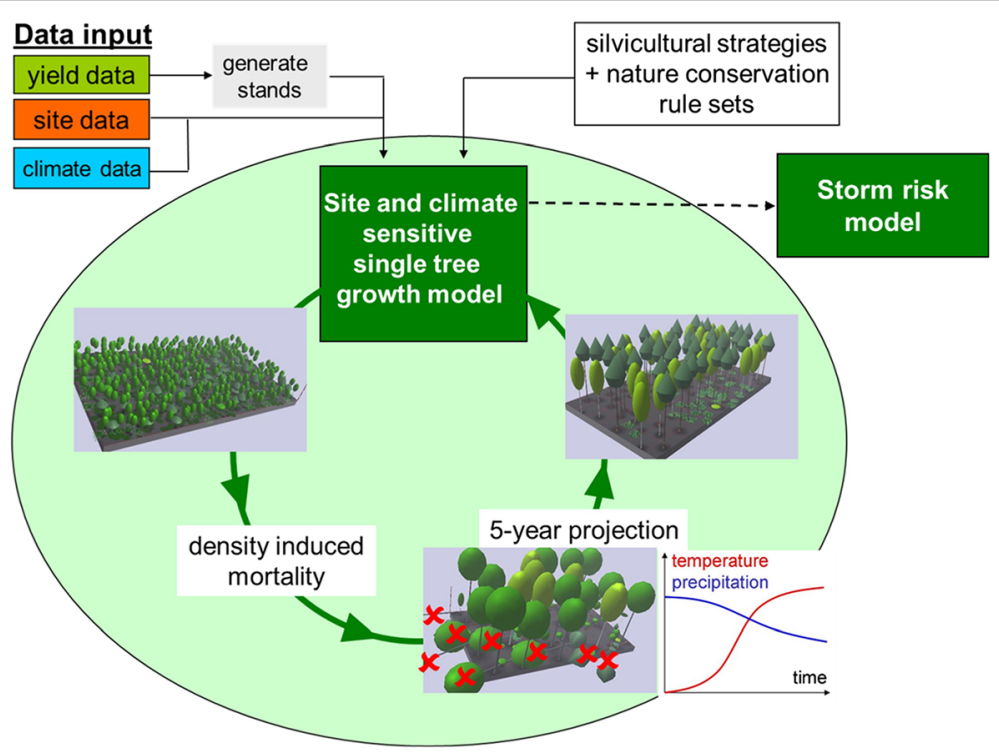

Figure 3 Representation of the major components of the Waldplaner simulation framework. 
Table 4 Characteristics of selected control variables defining the three silvicultural management strategies reference, biodiversity and climate protection and the according nature conservation rule sets

\begin{tabular}{|c|c|c|c|c|}
\hline & Control variable & Reference & Biodiversity & Climate protection \\
\hline \multirow[t]{4}{*}{ Nature conservation } & Unmanaged area & Status quo & $5 \%$ of forest area & Status quo \\
\hline & $\begin{array}{l}\text { Area under flora-fauna- } \\
\text { habitat (FFH) directive }\end{array}$ & $\begin{array}{l}45 \% \text { of the } \mathrm{FFH} \text {-area as } \\
\text { natural habitat type }\end{array}$ & $\begin{array}{l}100 \% \text { of the FFH-area as } \\
\text { natural habitat type }\end{array}$ & $\begin{array}{l}45 \% \text { of the } \mathrm{FFH} \text {-area as } \\
\text { natural habitat type }\end{array}$ \\
\hline & Deadwood $\left(\mathrm{m}^{3} \cdot \mathrm{ha}^{-1}\right)$ & 20 & 40 & 20 \\
\hline & Habitat tress $\left(\mathrm{N} \cdot \mathrm{ha}^{-1}\right)$ & 3 & 10 & 3 \\
\hline Species conversion & $\begin{array}{l}\text { Selection of future stand } \\
\text { type }\end{array}$ & $\begin{array}{l}\text { Dominating deciduous } \\
\text { species }\end{array}$ & $\begin{array}{l}\text { Tree species of potential } \\
\text { natural vegetation (pnv) }\end{array}$ & Dominating conifer species \\
\hline \multirow[t]{4}{*}{ Thinning } & Thinning intensity & $\begin{array}{l}\text { Variable over time: high, } \\
\text { moderate, low }\end{array}$ & Moderate & $\begin{array}{l}\text { Variable over time: } \\
\text { high, moderate, low }\end{array}$ \\
\hline & Thinning type & Thinning from above & Thinning from above & Thinning from above \\
\hline & $\begin{array}{l}\text { Start of thinning (defined } \\
\text { by stand height) }\end{array}$ & $12-16 \mathrm{~m}$ & $12-16 \mathrm{~m}$ & $11-15 \mathrm{~m}$ \\
\hline & $\begin{array}{l}\text { Limit of thinned volume } \\
\text { per cut }\left(\mathrm{m}^{3} \cdot \mathrm{ha}^{-1}\right)\end{array}$ & Max 70 (Douglas-fir max 100) & Max 50 (Douglas-fir max 100) & $\begin{array}{l}\text { Max } 70 \text { (Douglas-fir } \\
\max 100)\end{array}$ \\
\hline \multirow[t]{2}{*}{ Harvest } & Target diameter (cm) & $\begin{array}{l}\text { Oak } 70 \text {, beech } 60, \text { spruce } 45, \\
\text { pine } 45, \text { Douglas-fir } 70\end{array}$ & $\begin{array}{l}\text { All species }+5 \mathrm{~cm} \text {, in FFH- } \\
\text { areas }+10 \mathrm{~cm} \text { except } \\
\text { spruce }-5 \mathrm{~cm} \text {, Douglas-fir }-10 \mathrm{~cm}\end{array}$ & All species $-5 \mathrm{~cm}$ \\
\hline & $\begin{array}{l}\text { Limit of harvested volume } \\
\text { per cut }\left(\mathrm{m}^{3} \cdot \mathrm{ha}^{-1}\right)\end{array}$ & Max 100 (Douglas-fir max 120) & $\begin{array}{l}\text { Max } 70 \text { (max } 100 \text { for all species } \\
\text { not included in pnv) }\end{array}$ & $\begin{array}{l}\text { Max } 100 \text { (Douglas-fir } \\
\max 120)\end{array}$ \\
\hline
\end{tabular}

at the effects of management paths and climate projections on windthrow probability and drought stress. To evaluate windthrow probability, a storm risk model is linked to the simulation framework. After each 5-year cycle the single-tree windthrow probability can be predicted based on the current stand and constant site conditions.

\section{Storm risk model}

The risk of windthrow is predicted using the binary additive regression model with explicit spatial component by Schmidt et al. (2010). The storm risk model predicts the probability of windthrow for single trees based on the tree-specific variables species, height and $\mathrm{dbh}$, on the topographic variable Topex-to-distance index with a marginal distance of $1000 \mathrm{~m}$ in a modified version to the original by Scott and Mitchell (2005), on site conditions characterized by three waterlogging classes and on a spatial proxy for flow field information (wind speed). The storm risk model is parameterized for the species groups European beech - oaks, other deciduous species, Norway spruce, Scots pine - larches, Silver fir Douglas-fir.

The model proves most sensitive to tree height, while height-diameter ratio has a much lower effect on windthrow probability. With all other factors constant Norway spruce is most prone to windthrow followed by the Silver fir - Douglas-fir group and the Scots pine larches group. Deciduous species are generally less susceptible to windthrow than conifers.
Furthermore, the model is highly sensitive to terrain exposure interacting with cardinal direction. In our four model regions, the terrain merely shows distinctive relief. Therefore, in our predictions of windthrow probability Topex-to-distance index and the accompanying cardinal direction play an inferior role.

The model is initialized for predictions using the current and future stocking, the specific terrain exposure and cardinal direction of the sample point centre and a constant spatial proxy representing gale wind speed. Furthermore, we simulate a winter storm with southwestern direction.

\section{Drought stress}

Drought stress is seen as an important hazard impinging on tree vitality, growth potential and ultimately even mortality (Hanson and Weltzin 2000; Allen et al. 2010). Different definitions and assessment methods for drought stress exist (Farooq et al. 2009; Anderegg et al. 2013). Considering the data available to us we define drought stress using the water available to plants in the growing season as an indicator (Spellmann et al. 2007). For this purpose, water available to plants (wap) is estimated as the sum of climatic water balance $(c w b)$ in the growing season and the available soil moisture (asm). Climatic water balance, furthermore, is the difference between the precipitation and the potential evapotranspiration of grass. As an advantage the variable wap can easily be derived spatially comprehensive. Based on the mean wap-values of a 20-year period (1991 to 2010 as 
status quo, and the three projection periods 2011 to 2030, 2031 to 2050 and 2051 to 2070) it is possible to assess a drought stress indicator at each site in the study regions over time under the three climate projections.

The continuous variable wap is further transformed into risk classes (Spellmann et al. 2011). The derivation of the species-specific wap-range is crucial for the drought stress assessment. The ranges and drought stress classes are assessed based on (1) the correlation between growth potential and water regime, (2) an analysis of observed species distribution ranges depending on water availability as well as (3) expert knowledge on the cultivation of species under different water regimes in northern Germany (Table 5).

This drought stress classification is used in strategic planning when evaluating species suitability for cultivation. The interpretation of the three classes is straightforward. No restrictions apply when low drought risk is assigned. On sites with a medium drought risk the respective species should not be planned as leading species but possibly as associated species. Where high drought risk is predicted, the respective species should not be planned at all or at the most as secondary species.

The values in Table 5 indicate Norway spruce as most prone to drought stress, followed by European beech, oak and Douglas-fir and Scots pine as most resistant. For a complete drought risk assessment in the study regions, other tree species are assigned to one of the four species classifications.

\section{Results}

The risk profile of a forest region, in particular windthrow risk and drought stress, is determined by site parameters, climate conditions and forest characteristics in terms of e.g. species composition, age class distribution, standing volume, growth potential. Silvicultural management strategies are the only direct option to control forest dynamics and thus impact future risks. Therefore, the analysis of forest dynamics in the silvicultural decision space defined by the three applied management strategies reference, climate protection and biodiversity is a prerequisite to interpret and understand risk analysis and to develop adaptation strategies. All following

Table 5 Definition of risk classes on drought stress based on water available to plants in the growing season for Norway spruce, European beech, sessile and pedunculate oak and Douglas-fir and Scots pine

\begin{tabular}{lllll}
\hline $\begin{array}{l}\text { Drought } \\
\text { stress }\end{array}$ & \multicolumn{4}{l}{ Water available to plants in growing season $(\mathbf{m m})$} \\
\cline { 2 - 5 } & Spruce & Beech & Oak/Douglas-fir & Pine \\
\hline Low & $>0$ & $>-25$ & $>-150$ & $>-180$ \\
Medium & 0 to -80 & -25 to -100 & -150 to -400 & -180 to -450 \\
High & $<-80$ & $<-100$ & $<-400$ & $<-450$ \\
\hline
\end{tabular}

reported results of forest dynamics and risk analysis are projected under the median climate scenario.

\section{Simulation approach 1: Forest dynamics}

Silvicultural operations like thinnings and harvests have an immediate impact on forest dynamics whereas conversion in species composition is a rather long-term process because only mature stands are harvested and potentially converted.

The age class structure defines the potential speed of forest conversion. The initial state of the proportion of crown cover for all species combined over age classes illustrates differences between the four regions in 2010 (Figure 4).

The age class distributions indicate a majority of young stands in Diepholz (Figure 4A), a peak at the mid-age stands in Uelzen and Oder-Spree (Figure 4B and D) and a rather balanced distribution in the Fläming region (Figure 4C). The status quo of the age class distribution is one important determinate when starting the simulation of forest development under the three silvicultural management strategies.

The development of standing volume and the corresponding harvested volume reflect medium-term forest dynamics (Figure 5 and Table 6).

The Oder-Spree region has the highest initial standing volume with an average of $275 \mathrm{~m}^{3} \cdot \mathrm{ha}^{-1}$ in 2010 followed by Fläming with $263 \mathrm{~m}^{3} \cdot \mathrm{ha}^{-1}$ and Uelzen with $261 \mathrm{~m}^{3} \cdot \mathrm{ha}^{-1}$. Diepholz has the lowest value with $175 \mathrm{~m}^{3} \cdot \mathrm{ha}^{-1}$ due to the bulge of young stands. The volume trends displayed in Figure 5 indicate for all regions that under the biodiversity management regime standing volume is highest, under the climate protection path the lowest and the volume development under the reference strategy in an intermediate position. In Diepholz, coming from a low level, all management paths result in an increase of standing volume over time with the reference and biodiversity runs almost identical. In Uelzen, the biodiversity strategy yields a steady increase in standing volume. Under the reference path, volume increases until 2030 and afterwards shows a reduction below the initial value in 2070. Standing volume under the climate protection strategy drops continuously to an overall minimum of $173 \mathrm{~m}^{3} \cdot \mathrm{ha}^{-1}$ in 2055 . In the Oder-Spree region under the reference management strategy, the standing volume is almost constant until 2030 and decreases steadily afterwards. The climate protection path reduces standing volume considerably at the beginning and volume accumulates from 2055 on to reach almost the same value as under the reference path in 2070 . The biodiversity run leads to an overall maximum of $338 \mathrm{~m}^{3} \cdot \mathrm{ha}^{-1}$ in 2040 followed by a volume reduction again. The standing volume trends in Fläming resemble the development in Oder-Spree being just on a lower level. 

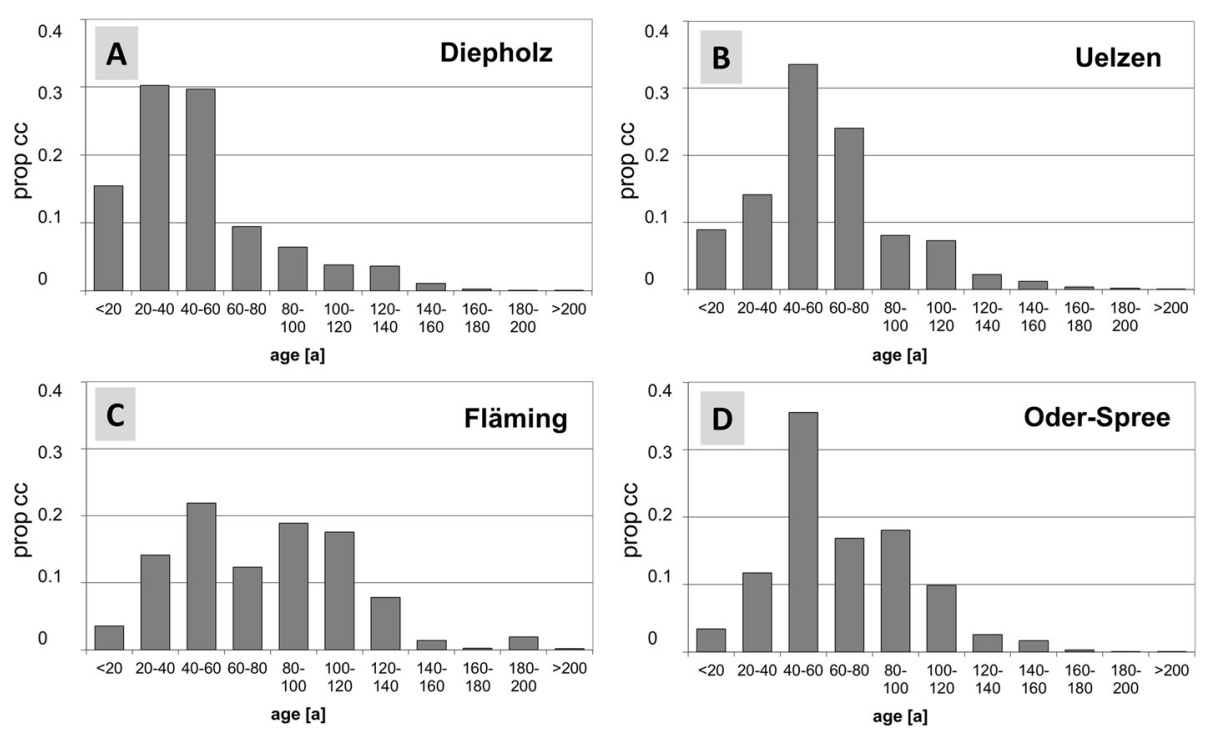

Figure 4 Proportion of crown cover (prop cc) for all species combined over age classes for the four regions Diepholz (A), Uelzen (B), Fläming (C) and Oder-Spree (D) in 2010.

The analysis of mean harvested volume in the four regions under the three silvicultural management strategies is complementary to standing volume development (Table 6). For all regions, the highest mean annually harvested volume is realized under the climate protection path, followed by the amount taken under the reference strategy and low intensity silviculture of the biodiversity run consequently yields the lowest mean harvested volume. Comparing the four regions, the most intense cuttings for all three management strategies are projected in the Uelzen region. Thinnings and harvests in Fläming and Oder-Spree yield almost the same mean annually harvested volume. The low values of harvested volume per cut in Diepholz reflect the projected volume accumulation.

Tree species composition of existing stands can gradually be changed by natural ingrowth or advance planting
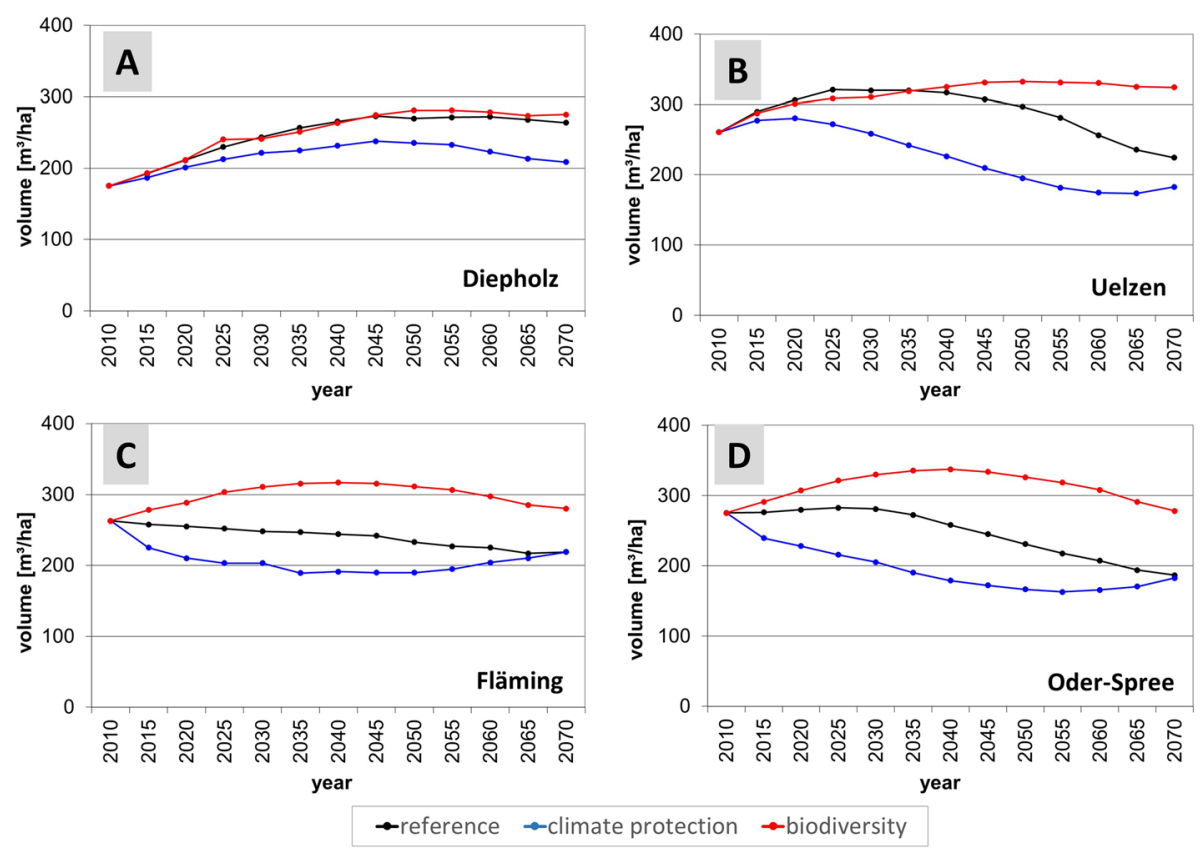

Figure 5 Development of standing volume $\left(\mathrm{m}^{3} \cdot \mathrm{ha}^{-1}\right)$ in the four regions Diepholz (A), Uelzen (B), Fläming (C) and Oder-Spree (D) under three silvicultural management regimes (black: reference, blue: climate protection, red: biodiversity) from 2010 until the end of the projection period in 2070 applying the median climate scenario. 
Table 6 Mean harvested volume $\left(\mathrm{m}^{3}\right.$ under bark $\left.\cdot \mathrm{ha}^{-1} \cdot \mathrm{a}^{-1}\right)$ for the four regions under the three silvicultural management strategies from 2010 until 2070 applying the median climate scenario

\begin{tabular}{lllll}
\hline & Diepholz & Uelzen & Fläming & Oder-Spree \\
\hline Reference & 4.2 & 6.3 & 5.9 & 6.0 \\
Climate protection & 5.0 & 7.0 & 6.3 & 6.6 \\
Biodiversity & 4.0 & 5.1 & 4.4 & 4.5 \\
\hline
\end{tabular}

and abruptly after harvesting the mature stand. The need for conversion arises mainly in regard to changing growth conditions due to climate change and because of the contrasting intentions of the three silvicultural management regimes. Generally, changes in species composition on the regional scale are a rather long-term process as shown in Table 7.

The current species composition in the four regions specified in Table 7 reveals a striking trend of increasing dominance of Scots pine in terms of crown cover proportion from west to east. While species composition in Diepholz is quite diverse with almost $50 \%$ of crown cover made up by other deciduous tree species, mostly birch, alder, poplar, the proportion of Scots pine in Uelzen already reaches $61 \%$. Uelzen nowadays has the highest proportion of Norway spruce (13\%) in comparison to the other regions. Both Diepholz and Uelzen have a considerable share of Douglas-fir which is almost entirely absent in the two eastern regions. In the Fläming region Scots pine dominates with almost $75 \%$ and only beech $(13 \%)$ and oak (6\%) have notable percentages. In Oder-Spree $81 \%$ of the crown cover derives from Scots pine, far behind are other deciduous species with $9 \%$ and oak with $6 \%$.

The changes in species proportions until 2070 in Table 7 show two overall findings: (1) comparing the three silvicultural scenarios the climate protection path has the highest conversion rate of species proportions and the biodiversity path the lowest in all regions and (2) comparing the four regions Uelzen has the highest conversion rates for all scenarios, Diepholz has the lowest rate under the reference path and Oder-Spree under the biodiversity path.

General tendencies for species are a preferential treatment of Douglas-fir under the climate protection and reference scenario. Beech and, to a lesser extent, oak are favoured by all silvicultural regimes in all regions, except oak in Uelzen under the climate protection path. The proportion of Scots pine is projected to decrease under all silvicultural scenarios in all regions except Diepholz where the crown cover proportion of Scots pine displays a considerable increase under the climate protection and even under the biodiversity path.

Analysing regional features in Diepholz under the climate protection regime, a strong reduction of other deciduous species' proportion is projected towards the more productive species beech, oak, spruce, pine and Douglas-fir. The reference settings simulate a similar

Table 7 Proportion of species crown cover based on the area of the respective region for European beech, sessile and pedunculate oak, all other deciduous species, Norway spruce, Scots pine, Douglas-fir and all other conifer species in 2010 and change in percentage points and the conversion rate in percent under the three silvicultural management strategies reference (ref), climate protection (cp) and biodiversity (bio) until $\mathbf{2 0 7 0}$ applying the median climate scenario

\begin{tabular}{|c|c|c|c|c|c|c|c|c|c|}
\hline & & Beech & Oak & Other deciduous & Spruce & Pine & Doug-fir & Other conifers & Conversion rate \\
\hline \multirow[t]{4}{*}{ Diepholz } & 2010 & $8.9 \%$ & $11.2 \%$ & $45.2 \%$ & $6.0 \%$ & $19.3 \%$ & $4.1 \%$ & $5.4 \%$ & \\
\hline & ref 2070 & +5.1 & +2.1 & -4.7 & -0.8 & -0.9 & +1.1 & -2.0 & 8.3 \\
\hline & ср 2070 & +7.8 & +3.0 & -25.0 & +2.1 & +7.4 & +5.9 & -1.4 & 26.2 \\
\hline & bio 2070 & +0.2 & +4.6 & -2.5 & -2.2 & +2.8 & -1.5 & -1.5 & 7.6 \\
\hline \multirow[t]{4}{*}{ Uelzen } & 2010 & $4.8 \%$ & $6.1 \%$ & $8.7 \%$ & $13.3 \%$ & $61.3 \%$ & $3.9 \%$ & $1.9 \%$ & \\
\hline & ref 2070 & +7.0 & +1.6 & +2.3 & -6.7 & -17.7 & +13.3 & -0.1 & 24.2 \\
\hline & cp 2070 & +14.7 & -0.9 & -1.5 & -8.9 & -34.1 & +26.8 & +4.0 & 45.5 \\
\hline & bio 2070 & +8.0 & +0.2 & +0.6 & -5.6 & -3.2 & +0.4 & -0.4 & 9.2 \\
\hline \multirow[t]{4}{*}{ Fläming } & 2010 & $12.8 \%$ & $5.9 \%$ & $4.3 \%$ & $1.8 \%$ & $73.5 \%$ & $0.4 \%$ & $1.2 \%$ & \\
\hline & ref 2070 & +8.3 & +2.5 & -0.4 & -0.8 & -11.2 & +1.9 & -0.2 & 12.7 \\
\hline & cp 2070 & +8.4 & +1.9 & -1.2 & -1.1 & -30.2 & +18.5 & +3.8 & 32.6 \\
\hline & bio 2070 & +5.9 & +0.7 & +1.1 & +1.6 & -9.2 & $+/-0$ & $+/-0$ & 9.3 \\
\hline \multirow[t]{4}{*}{ Oder-Spree } & 2010 & $2.0 \%$ & $5.7 \%$ & $8.8 \%$ & $1.1 \%$ & $80.9 \%$ & $0.5 \%$ & $1.0 \%$ & \\
\hline & ref 2070 & +7.1 & +2.9 & -1.8 & -0.1 & -8.3 & +0.3 & -0.1 & 10.3 \\
\hline & cp 2070 & +7.1 & +3.4 & -3.8 & -0.2 & -23.1 & +12.9 & +3.6 & 27.0 \\
\hline & bio 2070 & +0.7 & +0.4 & +0.7 & +0.4 & -2.1 & -0.1 & +0.1 & 2.3 \\
\hline
\end{tabular}


trend on a lower level without favouring spruce, pine and Douglas-fir. The biodiversity run projects only small changes mainly preferring oak. In Uelzen, all silvicultural management regimes simulate a reduction of spruce and pine proportions in favour of beech and Douglas-fir which is especially privileged under the climate protection $(+27$ percentage points) and reference run $(+13$ percentage points). In the Fläming region the proportion of Scots pine decreases under all silvicultural regimes especially preferring beech, oak and Douglas-fir and additionally under the biodiversity path also increasing the proportions of deciduous species and Norway spruce. The somewhat unexpected increase of Norway spruce results mainly from a conversion towards mixed stands with $90 \%$ beech and $10 \%$ spruce. In Oder-Spree, under the biodiversity strategy, almost no changes in species composition are projected. The climate protection and reference paths result in increasing proportions of beech, oak and Douglas-fir at the expense of Scots pine and other deciduous species.

\section{Simulation approach 1: vulnerability analysis}

Risk assessment on a regional scale aims at determining the need for adaptation measures and identification of the causes for high risk. Thus, after quantifying windthrow and drought risk, we focus on the effects of the three management strategies on both risk factors, as silvicultural treatments in general offer a direct and immediate access to reduce risks.

\section{Windthrow risk}

Species composition and age class structure, i.e. tree heights, significantly influence the windthrow risk on a regional scale. For forest management, in order to anticipate adaptation measures, it is more meaningful to investigate the windthrow probability of the most vulnerable stands or cohort of trees than looking at the mean risk value. Thus, in a first analysis, the mean windthrow probability of the $20 \%$ volume quantile of trees with the highest predicted single-tree windthrow probabilities are calculated for each region under the three silvicultural management strategies in 2010, 2030, 2050 and 2070 (Figure 6).

Figure 6 reveals some variability between the management paths over time for the Diepholz and Uelzen regions (Figure 6A and B), whereas no significant differences between the silvicultural regimes are noticeable for the Fläming and Oder-Spree regions (Figure $6 \mathrm{C}$ and $\mathrm{D}$ ). Currently, the highest mean windthrow probability of the $20 \%$ volume quantile exists in Uelzen followed by Diepholz and both eastern regions on the same level. Over time in Diepholz the reference strategy displays the highest probabilities followed by the climate protection path and the biodiversity strategy. While in Diepholz the probabilities decrease in the second and third projection period, there is a steady increase in Uelzen with similar values under the reference and climate protection path in 2070 and under the biodiversity strategy with considerably lower probability. In the Fläming and Oder-Spree regions all management
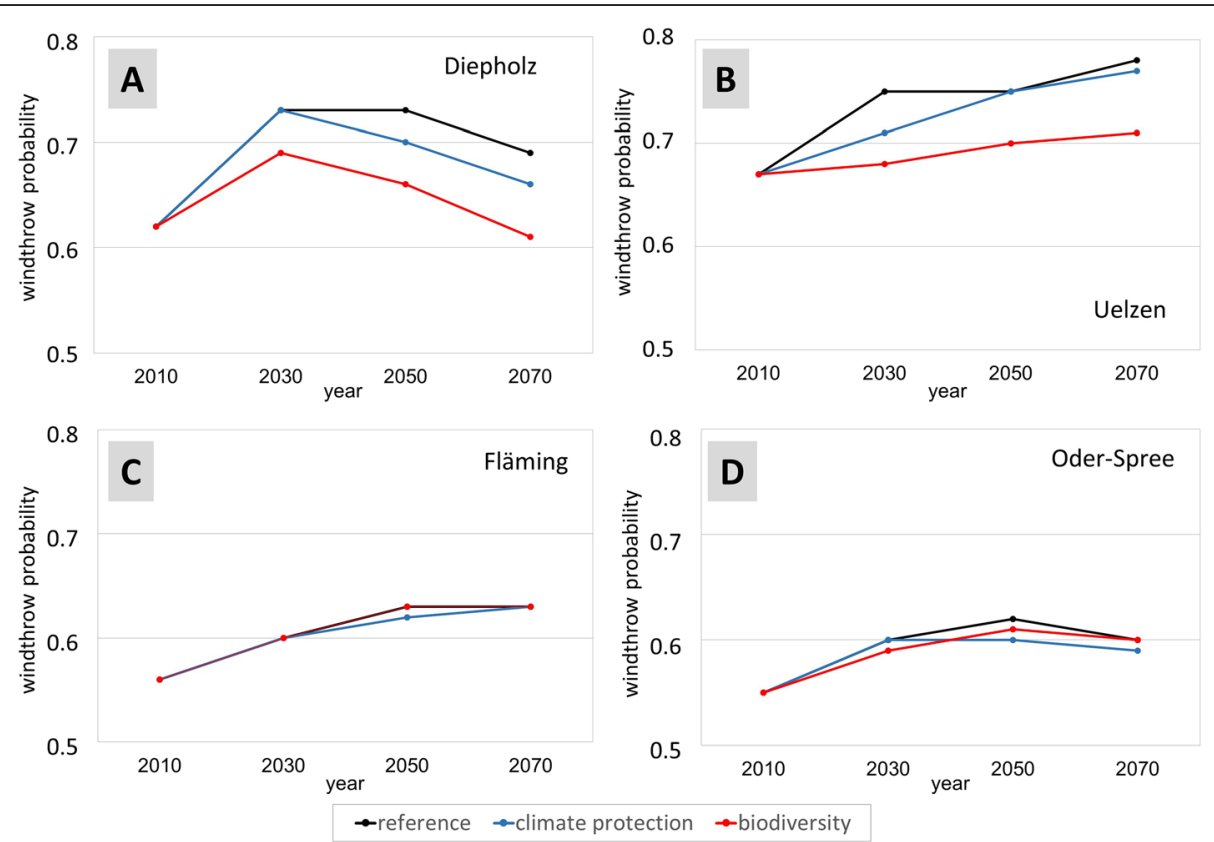

Figure 6 Mean volume-weighted windthrow probability over time in the four regions Diepholz (A), Uelzen (B), Fläming (C) and Oder-Spree (D) under the three silvicultural management scenarios (black: reference, blue: climate protection, red: biodiversity) applying the median climate scenario. 
scenarios result in quite similar probability values which slightly increase over time.

A closer species-specific analysis of windthrow risk in Uelzen reveals more detailed differences among the management paths than the mean windthrow probability of the $20 \%$ volume quantiles (Figure 7 ).

Figure 7 shows species-specific volume proportions over windthrow probability classes in Uelzen. Thus, each species' contribution to windthrow risk can be quantified directly. Scots pine dominates the current distributions in probability classes 0.4 to 0.6 (Figure 7A). Also considerable peaks in higher probability classes 0.7 to 0.9 exist for Norway spruce. A shift in distributions from 2010 to 2070 reflects changes in species composition due to the different silvicultural management paths as well as tree height growth. Under the reference path (Figure 7A) Douglas-fir shows a peak in a high probability class and a considerable volume proportion is made up by Scots pine in medium to increased probability classes in 2070. Under the climate protection regime, however, the volume at risk is distributed over many probability classes from 0.5 to 0.9 for pine and Douglas-fir (Figure 7C). Contrary, windthrow risk under the biodiversity strategy is solely dominated by Scots pine in the probability classes 0.6 and 0.7 (Figure 7D).

\section{Drought risk}

Changing climatic conditions heavily impact drought stress as reduced precipitation and higher temperatures intensify the risk of growth depressions, loss of vitality or even dieback. Therefore, keeping the climatic factor constant in order to better analyse the effect of silvicultural management regimes on drought risk, all reported results are generated under the median climate scenario. Also, species' susceptibility to drought stress varies significantly. Consequently, shifts in species composition due to different silvicultural management regimes and changing climate conditions affect the regional drought risk over time. Furthermore, regionally different soil properties, namely available soil moisture, contribute to different drought risks in the four regions. A first overview of drought risk is given in Figure 8.

As a general trend, in all regions and under every management strategy, a shift towards higher drought risk classes in the future is projected. However, obviously for all four regions, there are no significant differences between the risk class distributions of the three different silvicultural management strategies in 2070. Rating the four regions, Diepholz (Figure 8A) currently and in 2070 has the least overall drought risk closely followed by Uelzen (Figure 8B), although here already noticeable volume proportion are classified as high drought risk prone in all three silvicultural regimes. In both regions there seems to be no strong need for extensive adaptation measures regarding only drought risk under the assumed forest dynamics and climate projection. In the Oder-Spree region (Figure 8D) and even more in Fläming (Figure 8C) a considerable volume proportion is projected to be at risk in 2070 . To ensure future forest productivity in the two eastern regions measures to counter drought stress seem advisable.
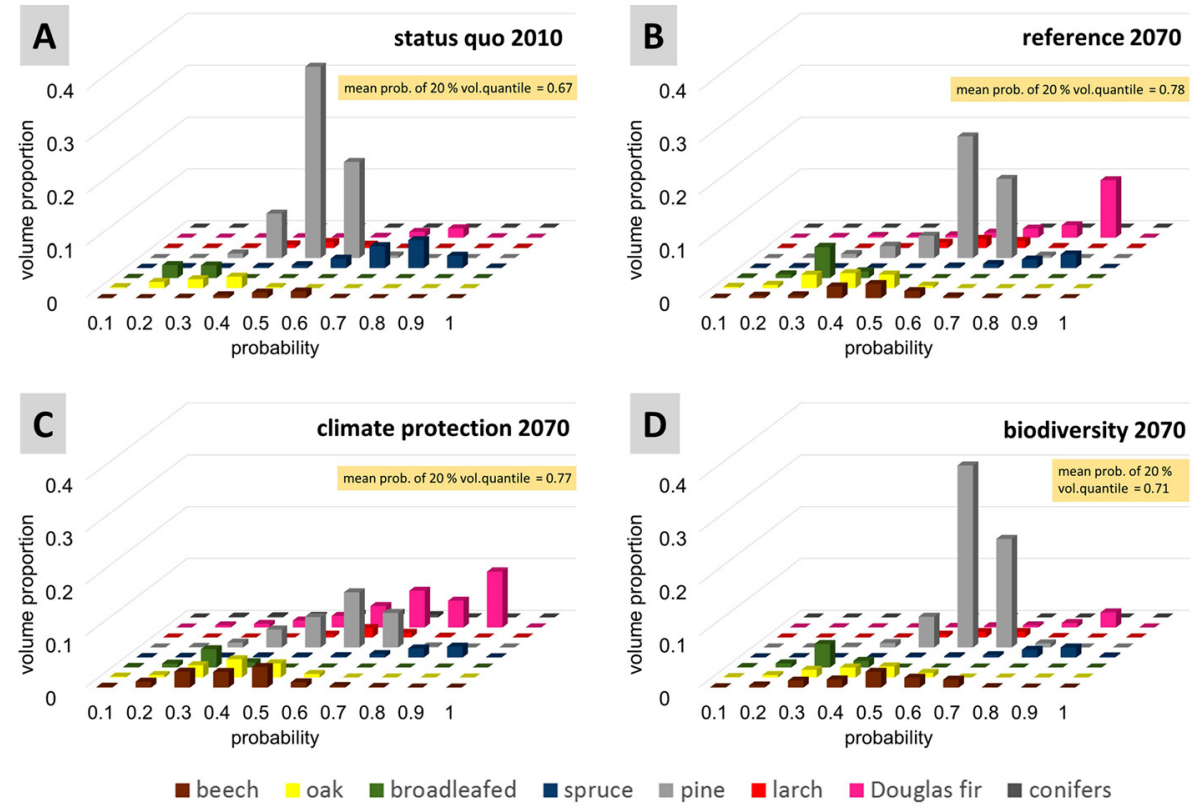

Figure 7 Distribution of species-specific volume proportions over windthrow risk classes in Uelzen for status quo conditions (A) and under the three silvicultural management strategies in 2070 (B, C and D) applying the median climate scenario. 

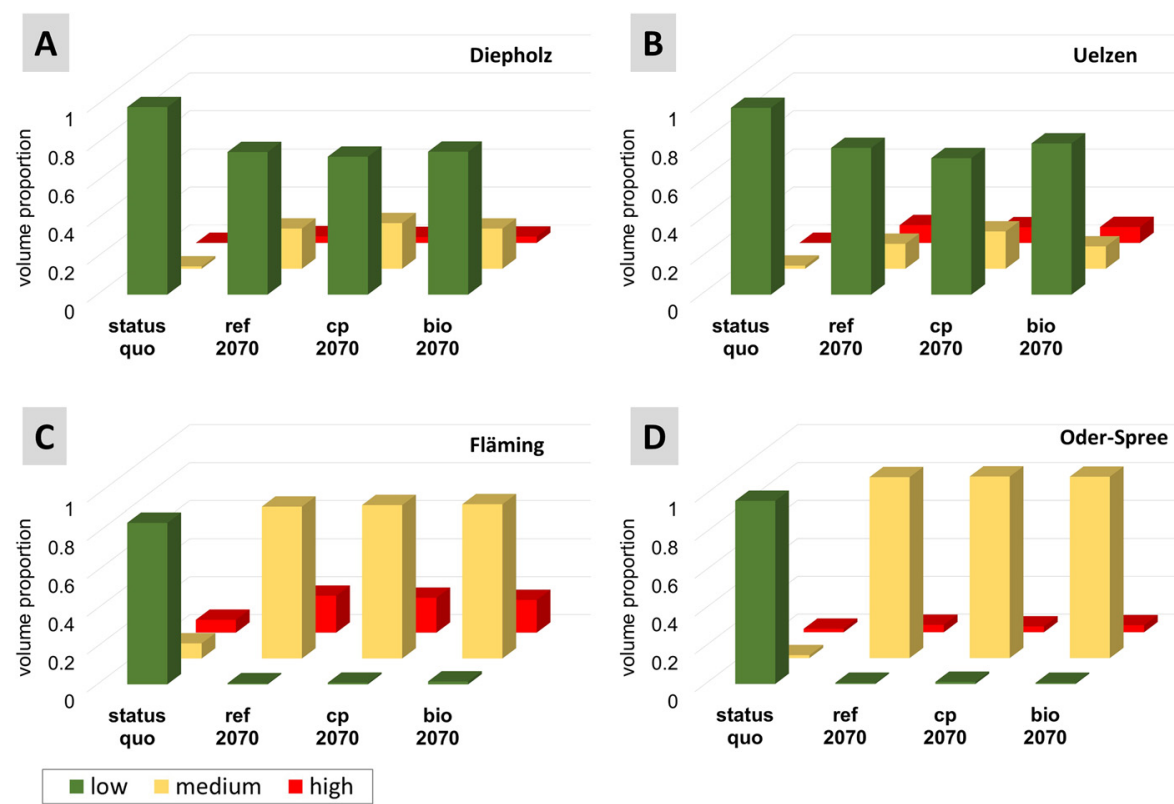

Figure 8 Distribution of volume proportions (all species combined) over drought risk classes in the four regions Diepholz (A), Uelzen (B), Fläming (C) and Oder-Spree (D) for status quo conditions and under the three silvicultural management strategies reference (ref), climate protection (cp) and biodiversity (bio) in 2070 applying the median climate scenario.

A species-specific analysis of drought risk development over time is essential to fathom adaptation options to reduce drought risk on a regional scale (Figure 9).

The example illustrates how regional drought risk is distributed between species in Fläming over time (Figure 9). This detailed drought risk assessment helps to better identify starting-points for adaptation measures. The distribution of species-specific volume proportions over drought risk classes for status quo conditions (Figure 9A) reveals that nowadays drought stress is no contemporary issue in the region, only beech with a total volume proportion of $12 \%$ contributes to the medium and high risk classes. In 2030 (Figure 9B), the drought risk assessment is unchanged but in 2050 (Figure 9C) there is a major shift in the classification of Scots pine and oak to the medium risk class and beech is entirely classified as highly drought risk prone. In 2070 (Figure 9D), virtually no volume proportion displays low risk but $80 \%$ made up by oak, pine, Douglas-fir and larch are under medium drought risk. Beech, accounting for the remaining $20 \%$, is highly threatened by drought stress.

\section{Simulation approach 2: uncertainty analysis}

Forest dynamics can be controlled by silvicultural management scenarios to a certain extent. Other factors outside the scope of forestry's area of influence can also affect forest dynamics heavily. For example, changing climatic conditions impact various abiotic and biotic risk factors and account for shifts in growth potential. Climate projections, in turn, differ tremendously depending on the assumed emission scenario, the applied global climate model and even when downscaling climate projections using different regional climate models. Therefore, climatic conditions are a considerable source of uncertainty in the projection of forest development.

We investigate the effect of the different climate projections on the risk factor drought stress and on height growth applying the minimum, median and maximum climate run.

\section{Drought risk}

The climate parameters precipitation and temperature vary significantly depending on the climate scenario applied (see Figure 2). This consequently affects drought stress to a great extent, and the arising uncertainty in a regional drought risk assessment resulting from different climate projections can be quantified (Figure 10).

The interpretation of Figure 10 is straightforward. A square is displayed if the three climate projections minimum, median and maximum do not generate different volume proportions in one risk class at a time. For example, $3 \%$ of the volume is classified in the high risk class under all three climate scenarios in 2050. But for the medium risk class in 2050, for example, the lowest volume proportion observed is $51 \%$ and the highest value is $96 \%$. Thus, the uncertainty in this risk class is 45 percentage points.

Assuming the future climate values will be in the range defined by the three climate projections, then the future drought risk in the Oder-Spree region will be 


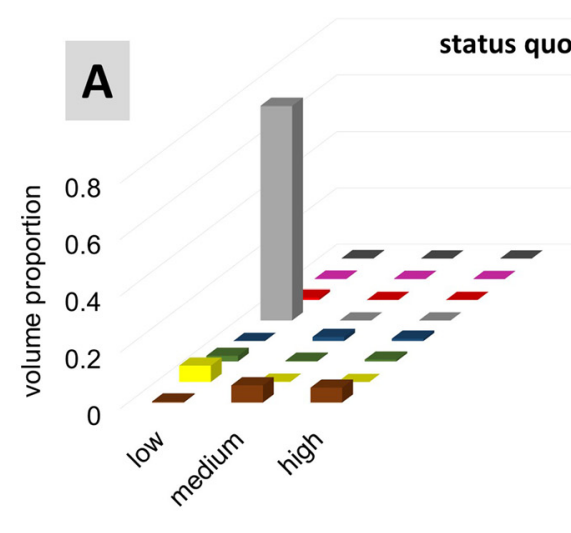

C

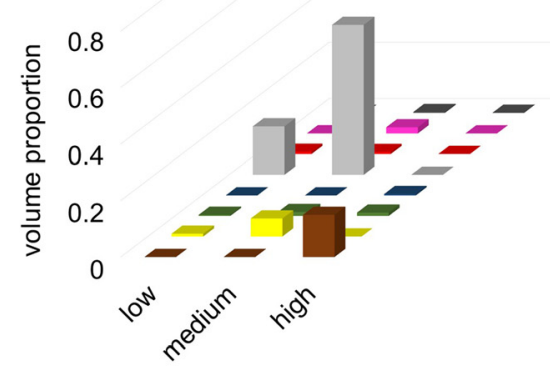

abeech oak abroadleafed aspruce

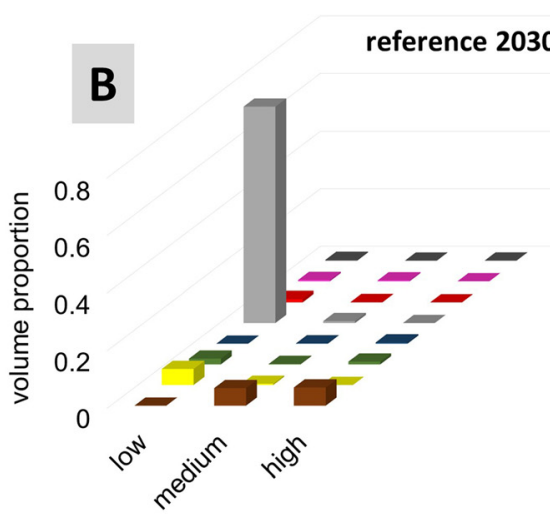

reference 2070

D

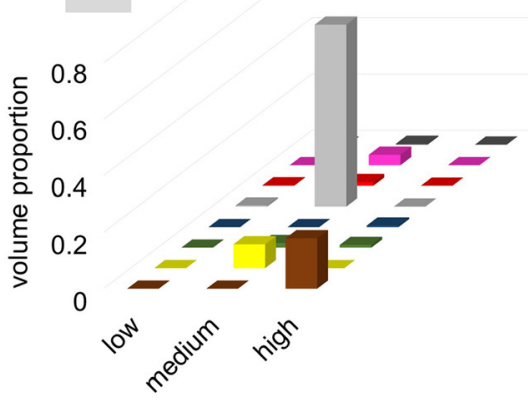

Figure 9 Distribution of species-specific volume proportions over drought risk classes in Fläming for status quo conditions (A) and under the reference scenario in 2030, 2050 and 2070 (B, C and D) applying the median climate scenario.

within the variability shown in Figure 10 when refraining from other sources of uncertainty.

\section{Height development}

Tree growth responds differently to changing climatic conditions. Depending on species, location, and site a moderate rise in temperature might enhance tree growth while decreasing precipitation will eventually result in reduced growth (Albert and Schmidt 2010; Pretzsch et al. 2014). Thus, it is important to evaluate the uncertainties in tree growth reaction to different climate projections (Figure 11).

Figure 11 illustrates the effects of different climate runs on periodic height increment of all trees remaining

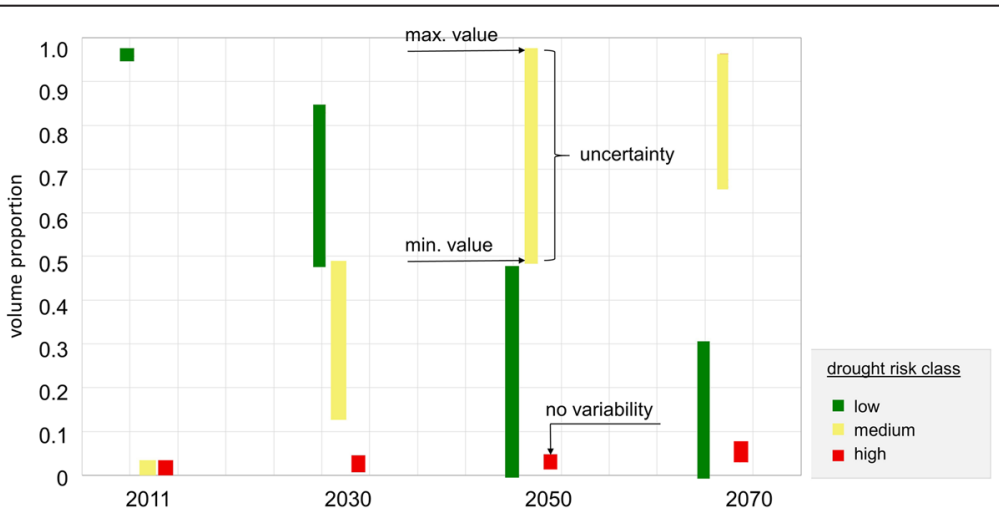

Figure 10 Variability in the distribution of volume proportions in drought risk classes over time for the Oder-Spree region applying the minimum, median and maximum climate run under the reference management scenario. 


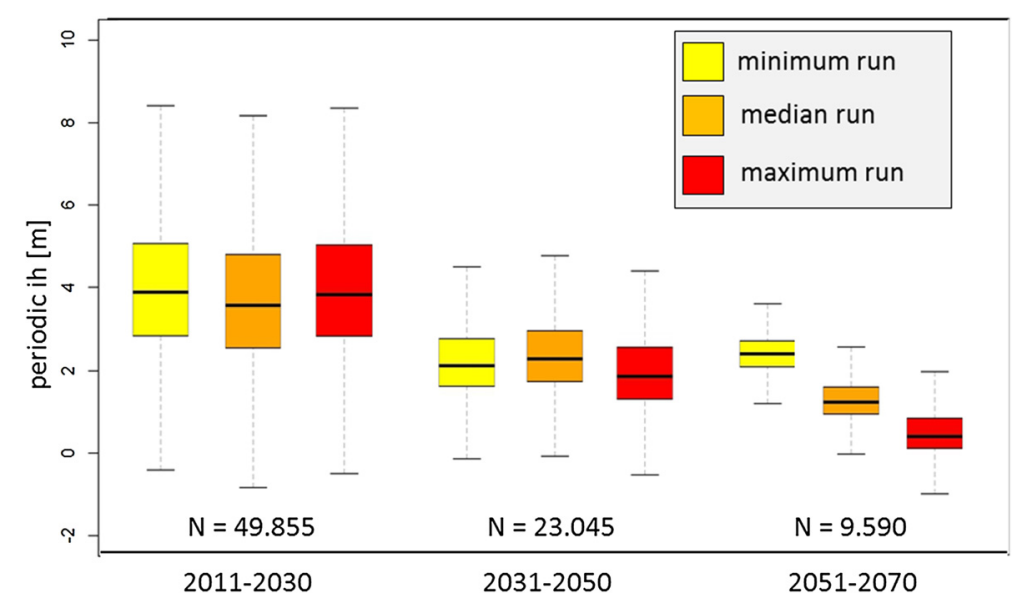

Figure 11 Boxplots of the 20 year periodic height increment of all trees remaining at the end of each projection period in the Oder-Spree region under the reference management scenario and applying the three climate runs.

at the end of each 20-year projection period under the reference management scenario in the Oder-Spree region. The analysis does not take ingrowth into account, thus, the collective of trees starting with almost 50,000 individuals shrinks to less than 10,000 at the end of the third projection period. Hence, differences between boxplots in one projection period are climatic effects, differences between periods are climatic and age effects. In the first two projection periods no trend in the climate effects on tree height growth can be observed. However, looking at the median value in the last projection period height increment under the minimum climate scenario is projected as $12 \mathrm{~cm}$ per year, under the median run as $6 \mathrm{~cm}$ per year and under the maximum run as $3 \mathrm{~cm}$ per year. Thus, the uncertainty on height growth in this case amounts to $9 \mathrm{~cm}$ per year for the median value.

When comparing the results between periods changing climate and proceeding age of the trees both contribute to the overall reduced level of height growth throughout the entire projection period until 2070 (Figure 11). A separate analysis distinguishes between both effects (Figure 12).

The analysis of periodic height increment clearly states the overwhelming influence of tree age on height growth (Figure 12). The decrease in height growth comparing the first three age classes outnumbers the climate induced effect. Trees older than 100 years, however, seem to react stronger on differences in the climatic conditions than on the aging effect.

\section{Discussion}

Various empirical and ecophysiological models exist to predict future hazards on forest ecosystems (e.g. Gadow 2001; Lindner et al. 2010). Thus, it is possible to detect potential hazards and to identify the most vulnerable areas in forest regions. The hazards can be further transformed into risks using probabilities. Risk is defined as the expected loss due to a particular hazard in a region during a defined time span (United Nations 1992). It is a major challenge to quantify the expected loss, for example assigning occurrence probabilities using quantitative approaches such as the applied storm risk model. However, such models are not always available. In that case Hirshleifer and Riley (1992) emphasize that risk is a situation in which subjective probabilities to hazard events are assigned depending on the stakeholder's expectation. The expectation reflects the stakeholder's risk attitude.

Applying scenario simulation, diverging effects of different silvicultural strategies on risks can be quantified (Clark et al. 2001). In forest planning models, risk factors can be considered as constraints to restrict the total risk level to a certain limit or to exclude certain risky management alternatives (Gadow 2000). Altogether, a comprehensive vulnerability analysis is of great importance to forest management in order to answer following questions according to the respective silvicultural management regime applied: (1) what are the major risk factors, (2) how will risk affect different forest functions, (3) is action needed for adaptation measures, and (4) what adaptation measures can be applied?

The presented risk assessment delivers insight into the effects of three silvicultural management strategies on two abiotic risk factors, windthrow and drought stress. To quantify these effects, we project forest development excluding interaction by mortality due to windthrow, loss of vitality or even mortality due to drought stress. In reality forest dynamics can substantially depart from this idealized projection.

\section{Windthrow risk}

The applied storm risk model (Schmidt et al. 2010) is a statistical approach utilizing variables which are generally 


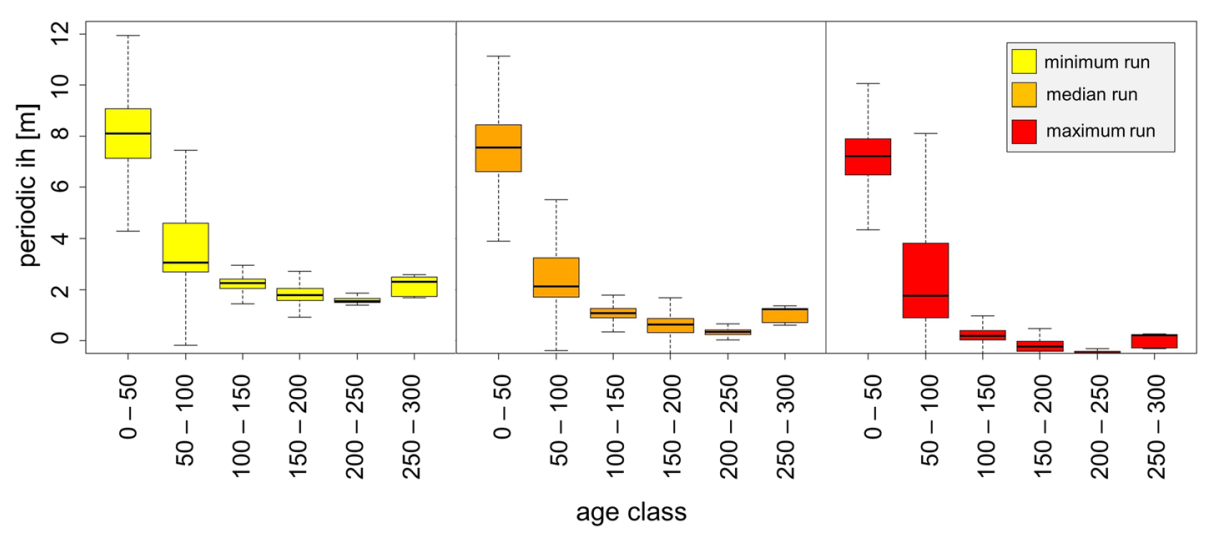

Figure 12 Boxplots of the 20 year periodic height increment over age classes in the Oder-Spree region in the projection period 2031 to 2050 under the reference management scenario and applying the three climate runs.

available in forestry for large areas. The information about single trees, stands and sites to predict windthrow probability is crucial to many different statistical model approaches such as the binary additive regression model used in this study, a discriminant model by Valinger et al. (1993), a logistic regression model by Kellomäki and Peltola (1998), and a neural network approach by Hanewinkel et al. (2004). In order to explain the causal relationship of wind damage to trees, most mechanistic model formulations require detailed information about physical as well as meteorological parameters (e.g. Peltola et al. 2013). Especially data characterizing wind fields and flow dynamics are not commonly available for risk projections in large forest areas, at least in our case. Therefore, the statistical storm risk model by Schmidt et al. (2010) is used in this study albeit knowing about the limitations when predicting windthrow probabilities in the north German lowlands while the model was parameterized using data from mainly southwestern German medium mountain ranges. Although the storm risk model does not predict windthrow probability climate-sensitively, assumptions on the frequency and intensity of storm events under climate scenarios alter the interpretation when transferring vulnerability probabilities into damages and losses. Further shortcomings of the model formulation are the lack of sensitivity to important factors such as species mixture, stand structure (c.f. Lüpke and Spellmann 1997; Griess et al. 2012) and also interaction with neighboring stands (c.f. Olofsson and Blennow 2005). Nevertheless, the projected ranking of species' sensitivity to windthrow vulnerability is mainly in accordance with other findings (Peltola et al. 1999; Bredemeier et al. 2001; Kohnle and Gauckler 2003; Schütz et al. 2006). The species effect on windthrow clearly shows that Norway spruce is most prone, followed by Scots pine, European beech and oak as well as other deciduous species. The susceptibility of Douglas-fir towards windthrow vulnerability is discussed controversially. Albrecht et al. (2012) conclude from their storm damage analysis that no differences between Norway spruce and Douglas-fir exist, while Schütz et al. (2006) argue in favor of Douglas-fir in mixed stands which is often the case in central Europe.

The implications from our windthrow vulnerability analysis for the four regions strongly depend on the individual risk attitude. Yet, no projections on storm frequencies and intensities are available. Thus, we can interpret the calculated windthrow probabilities by anticipating how many storm incidents will occur during the period regarded. Furthermore, a storm event will hardly hit an entire region equally. Whether or not a windthrow probability of $69 \%$ for the $20 \%$ volume quantile for the entire region of Diepholz under the reference path in 2070 calls for adaptation measures lies in the valuation of the decision maker. Nevertheless, the results of our analysis can contribute to depict windthrow vulnerabilities and possible counter-measures in the regions. Generally, the ranking of windthrow risk for the $20 \%$ volume quantile in the regions under the three silvicultural management scenarios is a result of conversion of different species as well as the different harvesting dimensions (c.f Tables 4 and 7).

The detailed example of the windthrow vulnerability analysis in the Uelzen region indicates that the climate protection management strategy is superior to the reference path as the volume at risk is divided more evenly between species, namely Douglas-fir and Scots pine, and also distributed over a broader range of probability classes (Figure 7). In terms of diversification of windthrow risk, the conversion from Scots pine to Douglas-fir in combination with a reduced target diameter harvest for all species is favorably on a regional level. Furthermore, species change to Douglas-fir will usually not result in pure stands but in mixtures mainly with European beech or Scots pine depending on soil nutrient supply. Species mixture will further enhance stand stability (Schütz et al. 
2006; Griess et al. 2012). Compared to the vulnerability assessment of the other two paths the biodiversity management strategy features only low volume proportions in the high probability classes. This is a clear advantage when only the most windthrow prone stands shall be converted.

If stakeholders nevertheless opt for the reference silvicultural management strategy in Uelzen because it might be preferable when considering other risk factors or management objectives windthrow risk reduction or prevention seems necessary. A substantial volume proportion of Douglas-fir and Norway spruce is predicted in high probability classes under the reference scenario in 2070 (Figure 7B). Considering only the most vulnerable species in the region the stakeholders have to decide whether or not action is necessary if about $10 \%$ of the total volume in the region has an $80 \%$ to $90 \%$ chance of windthrow in the case of a winter storm with gale wind speed. One possible adaptation measure could be species conversion. For example, Norway spruce stands could be converted to more stable deciduous species or at least mixed species stands. A second adequate measure could be reducing the target diameter, thus a lower harvesting age and consequently lower tree heights with lower windthrow risks. This is a feasible strategy which resembles an intermediate silvicultural management path between the reference and climate protection scenario. Next to the high windthrow risk of Norway spruce and Douglas-fir, Scots pine contributes the biggest share of endangered volume with a windthrow probability of $60 \%$ to $70 \%$ under the reference as well as the biodiversity strategy in 2070. Whether or not adaptation measures are necessary and economically worthwhile looking at the risk level and concerned species depends on the risk attitude of the decision maker. Possible adaptation measures might include conversions to deciduous species where soil conditions are favorable or enriching pine stands with deciduous species.

\section{Drought risk}

Modelling drought induced effects on forest ecosystems is a complex task. Anderegg et al. (2013) state that it is still not possible to reliably predict tree mortality triggered by drought based on easily available meteorological parameters. Adams et al. (2009) point out that mortality is a non-linear threshold process and thus being difficult to predict. Generally, trees react to drought incidents by primarily reduced productivity, a loss of vitality and at the same time a higher susceptibility to biotic hazards and even mortality (Hanson and Weltzin 2000). Obviously, species and individual trees experience different thresholds of soil moisture deficits leading to plant water stress and consequently resulting in physiological damage. Niinemets and Valladares (2006) present a drought tolerance classification for temperate northern hemisphere trees. Zang et al. (2011a) prove different stress responses of diameter increment depending on tree size for Scots pine, Norway spruce and oak. Also stand structure and species mixture plays an important role in species' reaction to drought. Pretzsch et al. (2012) show differences in species' tolerance and growth recovery under drought stress comparing pure and mixed forest stands. Furthermore, the interaction of environmental factors might influence the trees' reaction to drought stress. For example, with increasing temperature, water deficits of only short duration can trigger severe physiological damage (Adams et al. 2009).

The purpose of our drought risk assessment is to provide decision support on managing existing stands under climate change and to give recommendations for potential species conversions considering drought stress. Volume proportions in risk classes are quantified instead of predicting mortality or growth reduction. Hence, an adequately precise classification of drought risk should suffice to derive silvicultural adaptation measures and for strategic planning of species cultivation.

So, albeit far from being comprehensive, still lessons can be learnt from the results. The Diepholz region is climatically favored by enough precipitation and extensive areas with sufficient soil moisture. The forest area can best be characterized as a diverse species composition with a high proportion in young age classes. Thus, current vulnerability looking at drought stress is low. Also, under climate change no adaptation measures need to be considered in Diepholz as drought stress will be negligible until 2070. In Uelzen, today's site conditions are characterized by sufficient water for most species and a high proportion of fertile soils. Species distribution in Uelzen seems to be well adapted to the current situation. Under climate change Norway spruce, representing $13 \%$ of the area today, will be the most vulnerable species considering both drought risk and windthrow probability. Bredemeier et al. (2001), Hanewinkel et al. (2009), Spellmann et al. (2011) confirm the critical vulnerability rating of Norway spruce in Germany. The two eastern regions Fläming and Oder-Spree both are highly vulnerable to drought stress as, already today, the deficit in climatic water balance is substantial (see Table 2). Limitations on available water in combination with a high proportion of poor soil nutrient supply leaves a narrow margin of management alternatives for the future especially when considering the already overwhelming proportion of the most drought tolerant Scots pine.

Our evaluation of drought stress strongly relies on the derived risk class limits. Although evidence from observed species distribution ranges depending on water available to plants and conclusions from physiological drought experiments as well as drought assessments 
from literature are considered (e.g. Otto 1994; Roloff and Grundmann 2008; Kätzel et al. 2008) there is still the subjective element of setting the class boundaries in our classification. Considering the applied parameter water available to plants to evaluate drought stress there is just not sufficient knowledge from experiments or evidence from forest monitoring to warrant a more detailed drought risk classification by, for example, tree age or region. Nevertheless, other findings support our ranking from Norway spruce as most drought prone, followed by European beech, the group oak and Douglas-fir to Scots pine as most drought tolerant (Otto 1994; Bredemeier et al. 2001; Roloff and Grundmann 2008; Zang et al. 2011b). On the other hand, there is a controversial debate on drought tolerance of certain species, in central Europe especially European beech. For example, Rennenberg et al. (2004) regard European beech as highly vulnerable under climate change in central Europe whereas Ammer et al. (2005) conclude that beech will be competitive enough to dominate the potential natural vegetation in the future. Bolte et al. (2007) augment the debate with the argument that the high phenotypic plasticity and evolutionary adaptability of beech towards drought stress will be another competitive advantage. Eichhorn et al. (2008) analyzed the extreme dry and hot weather conditions in Germany in 2003 and conclude that European beech meets drought stress in the following year by shifting the carbon allocation towards pronounced fruit development and natural regeneration in order to secure species survival rather than individual biomass production. They conclude that adaptation of carbon allocation is an important indicator for drought stress tolerance.

Our drought risk analysis based on mean values (Figure 8) reveals whether or not action needs to be considered. The detailed species-specific analysis points to possible adaptation measures (Figure 9).

The example on drought risk analysis (Figure 8) uncovers a predicament in the results of the vulnerability analysis. Currently, in Diepholz and Uelzen no extensive adaptive measures seem necessary. In Fläming and Oder-Spree, a large volume proportion is predicted to be highly drought stress prone. Unfortunately, the more drought tolerant species Scots pine and oak already make up $70 \%$ of species area in Fläming and $85 \%$ in OderSpree leaving few potential for further increases. Furthermore, the high proportion of pine in the eastern regions might also bear intrinsic risks as other findings hint at a close relationship between climate change induced drought stress and Scots pine mortality as high summer temperatures along with drought may negatively shift the balance between trees and pathogens (Rebetez and Dobbertin 2004; Dobbertin et al. 2007). Also, simulation results by Lindner (2000) indicate that beech, due to its drought sensitivity, is not the best choice to transform pure Scots pine stands into mixed pine-deciduous species stands. Thus, although drought risk is an issue in the two eastern regions adaptation measures seem limited.

\section{Uncertainty}

Various definitions of uncertainty exist depending on discipline and also on context (Ascough et al. 2008). Furthermore, no unambiguous consensus on the characteristics, relative magnitude, and possible countermeasures exist, although many sources of uncertainty are identified. A more universal definition of uncertainty by Rowe (1994) is straightforward: the major attribute of uncertainty is the lack of information which may or may not be obtainable. Thus, every projection of forest dynamics and each decision process in natural resource management is connected to multiple uncertainties. Borchers (2005) calls for accepting uncertainty as it is better to identify factors of uncertainty and to include the effects on, for example, forest resources in the decision process rather than to strive for putative certainty. Such false certainty might be pretended by selecting, for example, one silvicultural strategy as irrevocably established and ignoring the multitude of possible management paths.

Generally, in the forestry domain three major sources of uncertainty are to be considered. Uncertainty may arise from sampling errors, measurement errors and prediction errors (Kangas and Kangas 2004). In our analysis we focus on the latter as we compare the effects of three climate projections on drought risk and height growth. The purpose of our uncertainty analysis is to quantify a range of possible outcomes. Especially in the case of climate projections, Jones (2000) precisely distinguishes between scenarios, forecasts and projected ranges of outcomes. In his definition a scenario is one possible projection with no probability assigned to it. A forecast, on the other hand, is the most likely projection with high probability and little uncertainty left. And eventually, a projected range of outcomes, as is the case in our analysis, includes uncertainties due to different probabilities. Of course, the probabilities of climate projections are unknown also in our analysis. The range of results simply illustrates the potential effects on, for example, drought risk or height growth. Using this information in the course of the decision process the forest manager might define his risk attitude and thus, consequently, assigns probabilities to the climate projections.

The uncertainty analysis in Oder-Spree (Figure 10) shows a high variability of drought risk on climate projections. In order to draw conclusions on the results and to opt for management alternatives, the quantified amount of uncertainty can be regarded as probabilities of future states. The stakeholders, thus, might look at 
the different climate projections as hazards. A risk-averse attitude assigns the climate run with the most negative impact on the forest ecosystem a high probability.

The second example on uncertainty concerns the variability of height growth due to climate projections (Figures 11 and 12). The uncertainty on height growth and thus forest productivity might have major implications for timber yield predictions affecting timber supply and income of forest enterprises (c.f. Hanewinkel et al. 2009) as well as ecological parameters, for example carbon sequestration and carbon offsets (c.f. Galik and Jackson 2009) or shifts in volume increment to mean tree volume allometry and number of trees to mean tree volume allometry (Pretzsch et al. 2014).

\section{Conclusions}

Simulation studies on forest dynamics applying the introduced simulation framework WaldPlaner are useful to evaluate the impact of different silvicultural management strategies and to analyse the effects of different climate projection on a regional level. We characterize the variation in forest development and assess the effects on drought and windthrow risk due to different silvicultural practices in four regions in the North German lowlands.

Drought risk is a serious issue in the eastern regions Fläming and Oder-Spree independently from the applied silvicultural scenario, but adaptation measures are limited as the proportion of the most drought tolerant species Scots pine is already high. Whether or not there will be a significant drought induced die-back even of pine is debatable (cf. Dobbertin et al. 2007). In any case, the area of less productive forests will increase.

Windthrow risk is no serious overall threat in any region, but adequate counter-measures such as species conversion, species mixture or reduction of target diameter can be taken where endangered stands are identified.

Furthermore, we quantify the amount of uncertainty in drought risk assessment and height growth arising from different climate projections. Taking adaptation measures to counteract climate induced uncertainty on e.g. drought risk or changes in productivity is a matter of individual risk attitude as the three climate runs span a decision space with possible developments.

The investigated projection period until 2070 suffice to detect changes, although being short of the proposed 100 -year simulation period as species conversion is a slow process (Lindner 2000). Based on the simulation results it is possible to give decision support for sustainable forest management and adaptation measures can be considered. Risk assessment, of course, is only one important contribution in the decision process on how to manage stands and about conversion strategies. Other factors such as forest productivity, timber supply, non- timber products even recreational value play an important role in a comprehensive decision process.

Obviously, the three contrasting management scenarios and the three climate projections investigated are only a small extract of multiple future paths. Other than in a forest management optimization process the contrasting scenarios define a decision space with quantified effects on forest dynamics, risks and uncertainties. Furthermore, forest management planning is always customised to local conditions. Therefore, none of the introduced silvicultural management paths will actually be assigned to the entire forest land of a region but forest management will strive for the best mixture.

Competing interests

The authors declare that they have no competing interests.

\section{Authors' contributions}

The first author (MA) conducted the data analysis and wrote the first draft. $\mathrm{HS}$ and JN initiated the research project "Sustainable land-use management in the North German lowlands". HS defined the silvicultural management regimes and provided major input to the drought risk analysis. JH provided and adjusted the WaldPlaner software. MS provided the longitudinal height diameter model and the storm risk model and had a major input in improving the manuscript. All authors jointly discussed the simulation results. All authors read and approved the final manuscript.

\section{Acknowledgements}

We thank Johannes Sutmöller and Bernd Ahrends for providing climate and soil data. We acknowledge Robert Nuske's assistance with acquiring the forest inventory data and its processing. Two anonymous reviewers' critical comments and constructive suggestions helped to improve the manuscript greatly. The presented research was funded by the German Federal Ministry of Education and Research under research grant 033LO29H.

Received: 5 December 2014 Accepted: 17 April 2015

Published online: 12 May 2015

\section{References}

Adams HD, Guardiola-Claramonte M, Barron-Gafford GA, Villegas JC, Breshears DD, Zhou CB, Troch PA, Huxman TE (2009) Temperature sensitivity of drought-induced tree mortality portends increased regional die-off under global-change-type drought. PNAS 106(17):7063-7066, doi:10.1073/ pnas.0901438106

Adger WN (2006) Vulnerability. Glob Environ Change 16:268-281, doi:10.1016/ j.gloenvcha.2006.02.006

Ahrends B (2010) Ableitung der Nährstoffziffer anhand von bodenphysikalischen und bodenchemischen Kenngrößen., http://www.dss-wuk.de/hintergrund/ modelle/naehrstoffmodell/

Albert M, Schmidt M (2010) Climate-sensitive modelling of site-productivity relationships for Norway spruce (Picea abies (L.) Karst.) and common beech (Fagus sylvatica L.). For Ecol Manage 259:739-749, doi:10.1016/ j.foreco.2009.04.039

Albrecht A, Kohnle U, Hanewinkel M, Bauhus J (2012) Storm damage of Douglas-fir unexpectedly high compared to Norway spruce. Annals For Sci 70(2):195-207, doi:10.1007/s13595-012-0244-x

Allen CD, Macalady AK, Chenchouni H, Bachelet D, McDowell N, Vennetier M, Kitzberger T, Rigling A, Breshears DD, Hogg EH, Gonzalez P, Fensham R, Zhang Z, Castro J, Demidova N, Lim J-H, Allard G, Running SW, Semerci A, Cobb N (2010) A global overview of drought and heat-induced tree mortality reveals emerging climate change risks for forests. For Ecol Manage 259:660-684, doi:10.1016/j.foreco.2009.09.001

Ammer C, Albrecht L, Borchert H, Brosinger F, Dittmar C, Elling W, Ewald J, Felbermeier B, Hv G, Huss J, Kenk G, Kölling C, Kohnle U, Meyer P, Mosandl R, Moosmayer H-U, Palmer S, Reif A, Rehfuess K-E, Stimm B (2005) Zur Zukunft der Buche (Fagus sylvatica L.) in Mitteleuropa. Allg Forst J Ztg 176(4):60-67 
Anderegg LDL, Anderegg WRL, Berry JA (2013) Not all droughts are created equal: translating meteorological drought into woody plant mortality. Tree Physiol 33(7):701-712, doi:10.1093/treephys/tpt044

Ascough IIJC, Maier HR, Ravalico JK, Strudley MW (2008) Future research challenges for incorporation of uncertainty in environmental and ecological decisionmaking. Ecol Modelling 219:383-399, doi:10.1016/j.ecolmodel.2008.07.015

Bolte A, Czajkowski T, Kompa T (2007) The north-eastern distribution range of European beech - a review. Forestry 80(4):413-429, doi:10.1093/forestry/cpm028

Bolte A, Ammer C, Löf M, Madsen P, Nabuurs G-J, Schall P, Spathelf P, Rock J (2009) Adaptive forest management in central Europe: Climate change impacts, strategies and integrative concept. Scan J For Res 24:473-482, doi:10.1080/02827580903418224

Borchers JG (2005) Accepting uncertainty, assessing risk: Decision quality in managing wildfire, forest resource values, and new technology. For Ecol Manage 211(1-2):36-46, doi:10.1016/j.foreco.2005.01.025

Bredemeier M, Lamersdorf N, Schulte-Bisping H, Lüpke B (2001) Risk Appraisal for Forest Management with Respect to Site Quality and Environmental Changes. In: Gadow K (ed) Risk analysis in Forest Management. Managing Forest Ecosystems, Vol. 2. Springer Science+Business Media, Dordrecht

Carlowitz HC (1713) Sylvicultura oeconomica. Braun Leipzig

Clark JS, Carpenter SR, Barber M, Collins S, Dobson A, Foley JA, Lodge DM, Pascual M, Pielke JR, Pizer W, Pringle C, Reid W, Rose KA, Sla O, Schlesinger WH, Wall DH, Wear D (2001) Ecological Forecasts: An Emerging Imperative. Science 293:657-659

de Martonne E (1926) Une nouvelle fonction climatologique: I'indice d'aridité. La Météorologie 21:449-458

Dobbertin M, Wermelinger B, Bigler C, Bürgi M, Carron M, Forster B, Gimmi U, Rigling A (2007) Linking increased drought stress to Scots pine mortality and bark beetle infestations. ScientificWorldJournal 7(S1):231-239, doi:10.1100/tsw.2007.58

Eichhorn J, Dammann I, Schönfelder E, Albrecht M, Beck W, Paar U (2008) Untersuchungen zur Trockenheitstoleranz der Buche am Beispiel des witterungsextremen Jahres 2003. In: Nordwestdeutsche Forstliche Versuchsanstalt (ed) Ergebnisse angewandter Forschung zur Buche. Beiträge aus der Nordwestdeutschen Forstlichen Versuchsanstalt, vol 2. Universitätsverlag Göttingen, Göttingen, pp 109-134

Farooq M, Wahid A, Kobayashi N, Fujita D, Basra SMA (2009) Plant drought stress: effects, mechanisms and management. Agronomy Sustain Dev, Springer (Germany) 29(1):185-212

Gadow K (2000) Evaluating risk in forest planning models. Silva Fennica 34(2):181-191

Gadow K (2001) Risk analysis in forest management. Managing Forest Ecosystems, vol. 2. Springer Science+Business Media, Dordrecht

Galik CS, Jackson RB (2009) Risks to forest carbon offset projects in a changing climate. For Ecol Manage 257:2209-2216, doi:10.1016/j.foreco.2009.03.017

Griess VC, Acevedo R, Härtl F, Staupendahl K, Knoke T (2012) Does mixing tree species enhance stand resistance against natural hazards? A case study for spruce. For Ecol Manage 267:274-296, doi:10.1016/j.foreco.2011.11.035

Hanewinkel M, Zhou W, Schill C (2004) A neural network approach to identify forest stands susceptible to wind damage. For Ecol Manage 196:227-243, doi:10.1016/j.foreco.2004.02.056

Hanewinkel M, Hummel S, Cullmann DA (2009) Modelling and economic evaluation of forest biome shifts under climate change in Southwest Germany. For Ecol Manage 259:710-719, doi:10.1016/j.foreco.2009.08.021

Hansen J, Nagel J (2014) Waldwachstumskundliche Softwaresysteme auf Basis von TreeGrOSS - Anwendungen und theoretische Grundlagen. Beiträge aus der Nordwestdeutschen Forstlichen Versuchsanstalt, vol 11. Universitätsverlag Göttingen, Göttingen

Hanson PJ, Weltzin JF (2000) Drought disturbance from climate change: response of United States forests. Sci Total Environ 262:205-220

Hirshleifer J, Riley JG (1992) The Analytics of Uncertainty and Information. Cambridge University Press, Cambridge

IPCC (2013) Climate Change 2013: The Physical Science Basis. Contribution of Working Group I to the Fifth Assessment Report of the Intergovernmental Panel on Climate Change [Stocker, T.F., D. Qin, G.-K. Plattner, M. Tignor, S.K. Allen, J. Boschung, A. Nauels, Y. Xia, V. Bex and P.M. Midgley (eds.)]. Cambridge, United Kingdom and New York, NY, USA: Cambridge University Press.

Jones RN (2000) Managing uncertainty in climate change projections - issues for impact assessment. Climate Change 45:403-419

Kangas AS, Kangas J (2004) Probability, possibility and evidence: approaches to consider risk and uncertainty in forestry decision analysis. For Pol Econ 6:169-188
Kätzel R, Löffler S, Möller K (2008) Zur physiologischen Anpassungsfähigkeit der Waldkiefer. In: Nordwestdeutsche Forstliche Versuchsanstalt (ed) Die Waldkiefer - Fachtagung zum Baum des Jahres 2007. Beiträge aus der Nordwestdeutschen Forstlichen Versuchsanstalt, vol. 2. Universitätsverlag Göttingen, Göttingen.

Kellomäki S, Peltola H (1998) Silvicultural strategies for predicting damage to forests from wind, fire and snow. Res Note 73. Faculty of Forestry, University of Joensuu, Finland

Kohnle U, Gauckler S (2003) Vulnerability of forests to storm damage in a forest district of south-western Germany situated in the periphery of the 1999 storm (Lothar), Proceedings International Conference 'Wind effects on trees'. University of Karlsruhe, Germany

Lappi J (1991) Calibration of height and volume equations with random parameters. For Sci 43(4):555-570

Lindner M (2000) Developing adaptive forest management strategies to cope with climate change. Tree Physiol 20:299-307

Lindner M, Maroschek M, Netherer S, Kremer A, Barbati A, Garcia-Gonzalo J, Seidl R, Delzon S, Corona P, Kolström M, Lexer MJ, Marchetti M (2010) Climate change impacts, adaptive capacity, and vulnerability of European forest ecosystems. For Ecol Manage 259:698-709, doi:10.1016/j.foreco.2009.09.023

Lüpke B, Spellmann H (1997) Aspekte der Stabilität und des Wachstums von Mischbeständen aus Fichte und Buche als Grundlage für waldbauliche Entscheidungen. Forstarchiv 68:167-179

Menzel A (1997) Phänologie von Waldbäumen unter sich ändernden Klimabedingungen - Auswertung der Beobachtungen in den Internationalen Phänologischen Gärten und Möglichkeiten der Modellierung von Phänodaten. Forstliche Forschungsberichte München 164:147

Millar Cl, Stephenson NL, Stephens SL (2007) Climate change and forests of the future: managing in the face of uncertainty. Ecol Appl 17(8):2145-2151

Moss R, Babiker M, Brinkman S, Calvo E, Carter T, Edmonds J, Elgizouli I, Emori S, Erda L, Hibbard K, Jones R, Kainuma M, Kelleher J, Lamarque J-F, Manning M, Matthews B, Meehl J, Meyer L, Mitchell J, Nakicenovic N, O'Neill B, Pichs R, Riahi K, Rose S, Runci P, Stouffer R, van Vuuren D, Weyant J, Wilbanks T, van Ypersele JP et al (2008) Towards New Scenarios for Analysis of Emissions, Climate Change, Impacts, and Response Strategies. Intergovernmental Panel on Climate Change, Geneva

Niinemets Ü, Valladares F (2006) Tolerance to shade, drought, and waterlogging of temperate northern hemisphere trees and shrubs. Ecol Mono 76(4):521-547

Niklińska M, Maryański M, Laskowski R (1999) Effect of temperature on humus respiration rate and nitrogen mineralization: Implications for global climate change. Biogeochemistry 44:239-257

Olofsson E, Blennow K (2005) Decision support for identifying spruce forest stand edges with high probability of wind damage. For Ecol Manage 207:87-98, doi:10.1016/j.foreco.2004.10.019

Orlowsky B, Gerstengarbe F-W, Werner PC (2008) A resampling scheme for regional climate simulations and its performance compared to a dynamical RCM. Theor Appl Climatol 92(3-4):209-223

Otto HJ (1994) Waldökologie. Verlag Eugen Ulmer, Stuttgart, p 391

Overbeck M, Schmidt M, Fischer C, Evers J, Schultze A, Hövelmann T, Spellmann $H$ (2011) Ein statistisches Modell zur Regionalisierung der nutzbaren Feldkapazität von Waldstandorten in Niedersachsen. Forstarchiv 82:92-100

Peltola H, Kellomäki S, Väisänen H, Ikonen V-P (1999) A mechanistic model for assessing the risk of wind and snow damage to single trees and stands of Scots pine, Norway spruce, and birch. Can J For Res 29:647-661

Peltola H, Gardiner B, Nicoll B (2013) Mechanics of wind damage. In: Gardiner B, Schuck A, Schelhaas J-M, Orazio C, Blennow K, Nicoll B (eds) Living with Storm Damage to Forests. What Science Can Tell Us Vol 3, European Forestry Institute. 31-38

Peters GP, Andrew RM, Boden T, Josep Canadell G, Ciais P, Le Quéré C, Marland G, Raupach MR, Wilson C (2013) The challenge to keep global warming below $2^{\circ} \mathrm{C}$. Nat Clim Chang 3:4-6

Pretzsch H, Schütze G, Uhl E (2012) Resistance of European tree species to drought stress in mixed versus pure forests: evidence of stress release by inter-specific facilitation. Plant Biol 15(3):483-495, doi:10.1111/j.14388677.2012.00670.x

Pretzsch H, Biber P, Schütze G, Uhl E, Rötzer T (2014) Forest stand growth dynamics in Central Europe have accelerated since 1870. Nat Comm 5(4967):1-10, doi:10.1038/ncomms5967

Rebetez M, Dobbertin M (2004) Climate change may already threaten Scots pine stands in the Swiss Alps. Theor Appl Climatol 79:1-9, doi:10.1007/ s00704-004-0058-3 
Rennenberg H, Seiler W, Matyssek R, Gessler A, Kreuzwieser J (2004) Die Buche (Fagus sylvatica L.) - ein Waldbaum ohne Zukunft im südlichen Mitteleuropa. Allg Forst J Ztg 175(10/11):210-224

Richter A, Adler GH, Fahrak M, Eckelmann W (2007) Erläuterungen zur nutzungsdifferenzierten Bodenübersichtskarte der Bundesrepublik Deutschland im Maßstab 1:1.000.000 (BÜK 1000 N, Version 2.3). Bundesanstalt für Geowissenschaften und Rohstoffe, Hannover

Roloff A, Grundmann BM (2008) Waldbaumarten und ihre Verwendung im Klimawandel. Archiv f Forstw u Ldschökol 42:97-109

Rowe WD (1994) Understanding Uncertainty. Risk Analysis, 14: 743-750. doi: 10.1111/j.1539-6924.1994.tb00284.x

Schmidt M (2010) Ein standortsensitives, longitudinales Höhen-DurchmesserModell als Lösung für das Standort-Leistungs-Problem in Deutschland. In: Nagel J (ed) Jahrestagung der Sektion Ertragskunde des DVFFA in Körbecke., Göttingen

Schmidt M, Hanewinkel M, Kändler G, Kublin E, Kohnle U (2010) An inventorybased approach for modeling single-tree storm damage - experiences with the winter storm of 1999 in southwestern Germany. Can J For Res 40:1636-1652, doi:10.1139/X10-099

Schulla J (1997) Hydrologische Modellierung von Flussgebieten zur Abschätzung der Folgen von Klimaänderung. Diss. 12018, ETH Zurich, pp 163 (in German with English summary)

Schulla J, Jasper K (2007) Model Description WaSIM-ETH. ETH technical report, Zurich

Schütz JP, Götz M, Schmid W, Mandallaz D (2006) Vulnerability of spruce (Picea abies) and beech (Fagus sylvatica) forest stands to storms and consequences for silviculture. Eur J Forest Res 125:291-302, doi:10.1007/s10342-006-0111-0

Scott RE, Mitchell SJ (2005) Empircal modelling of windthrow risk in partially harvested stands using tree neighbourhood and stand attributes. For Ecol Manage 218:193-209, doi:10.1016/j.foreco.2005.07.012

Seidl R, Rammer W, Lexer MJ (2010) Climate change vulnerability of sustainable forest management in the Eastern Alps. Climate Change. doi: 10.1007/ s10584-010-9899-1

Spellmann H, Sutmöller J, Meesenburg H (2007) Risikovorsorge im Zeichen des Klimawandels. AFZ-Der Wald 23:1246-1249

Spellmann H, Albert M, Schmidt M, Sutmöller J, Overbeck M (2011) Waldbauliche Anpassungsstrategien für veränderte Klimaverhältnisse. AFZ-Der Wald 11:19-23

Turner IIBL, Matson PA, McCarthy JJ, Corell RW, Christensen L, Eckley N, Hovelsrud-Broda GK, Kasperson JX, Kasperson RE, Luers A, Martello ML, Mathiesen S, Naylor R, Polsky C, Pulsipher A, Schiller A, Selin H, Tyler N (2003) Illustrating the coupled human-environment system for vulnerability analysis: Three case studies. PNAS 100(14):8080-8085, doi:10.1073/pnas.1231334100

United Nations Department of Humanitarian Affairs (1992) Internationally agreed glossary of basic terms related to disaster management. Geneva. http:// reliefweb.int/sites/reliefweb.int/files/resources/ 004DFD3E15B69A67C1256C4C006225C2-dha-glossary-1992.pdf

Valinger $E$, Lindqvist L, Bondesson L (1993) Assessing the risk of snow and wind damage from tree physical characteristics. Forestry 66(3):249-260, doi:10.1093/forestry/66.3.249

Walther A, Linderholm HW (2006) A comparison of growing season indices for the Greater Baltic Area. Int J Biometeorol 51:107-118

Wilpert K (1990) Die Jahrringstruktur von Fichten in Abhängigkeit vom Bodenwasserhaushalt auf Pseudogley und Parabraunerde : ein Methodenkonzept zur Erfassung standortsspezifischer Wasserstreßdisposition. Freiburger Bodenkundl Abhandlungen 24:184

Zang C, Pretzsch H, Rothe A (2011a) Size-dependent responses to summer drought in Scots pine, Norway spruce and common oak. Trees 26(2):557-569, doi:10.1007/s00468-011-0617-z

Zang C, Rothe A, Weis W, Pretzsch H (2011b) Zur Baumarteneignung bei Klimawandel: Ableitung der Trockenstress-Anfälligkeit wichtiger Waldbaumarten aus Jahrringbreiten. Allg Forst J Ztg 182(5/6):98-112

\section{Submit your manuscript to a SpringerOpen ${ }^{\circ}$ journal and benefit from:}

- Convenient online submission

- Rigorous peer review

- Immediate publication on acceptance

- Open access: articles freely available online

- High visibility within the field

- Retaining the copyright to your article

Submit your next manuscript at $>$ springeropen.com 